\title{
ESTIMATIVA DA EMISSIVIDADE ATMOSFÉRICA EM SANTO ANTÔNIO DO LEVERGER - MT
}

\author{
ENICILDO DEL DUCCAS MENDONÇA
}

Orientador: Prof. Dr. JOSÉ HOLANDA CAMPELO JÚNIOR

Dissertação apresentada à Escola
Superior "Luiz de Queiroz", da
Universidade de São Paulo, para
obtenção do Título de Mestre em
Agronomia - Área de Concentração:
Agrometeorologia.

$P \mid R A C I C A B A$

Estado de São Paulo - Brasil

Setembro de 1995 
Dados internacionais de Catalogaçāo na Publicaçāo (CIP)

Divisão de Biblioteca e Documentaçāo - CAMPUS "LUIZ DE QUEIROZ"/USP

Mendonça, Enicildo Del Duccas

Estimativa da emissividade atmosférica em Santo Antônio do Lever ger - MT. Piracicaba, 1995.

61p.

Diss. (Mestre) - ESALO

Bibliografia.

1. Atmosfera - Santo Antônio do Leverger (Mato Grosso) 2. Balanço de energia 3. Evapotranspiração 4. Radiação solar I. Escola Superior de Agricultura Luiz de Queiroz, Piracicaba

CDD $\quad 559.51$

551.5271 


\title{
ESTIMATIVA DA EMISSIVIDADE ATMOSFÉRICA EM SANTO ANTÔNIO DO LEVERGER - MT
}

\author{
ENICILDO DEL DUCCAS MENDONÇA
}

Aprovada em: 10/10/1995

Comissão julgadora:

Prof. Dr. José Holanda Campelo Júnior

Prof. Dr. Luiz Roberto Angelocci

Prof. Dr. Celso Luiz da Silva

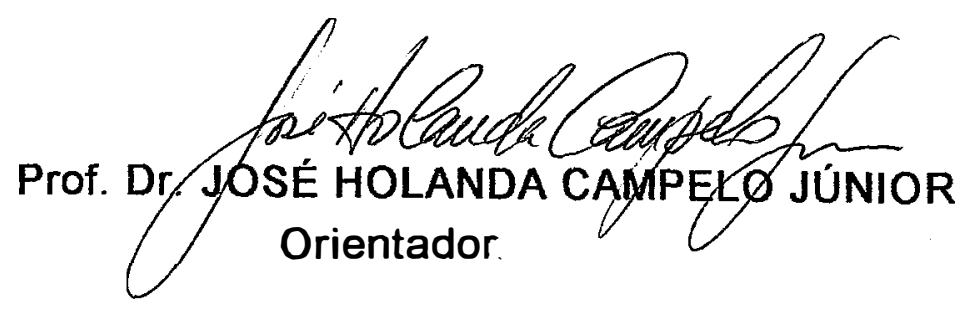




\section{AGRADECIMENTOS}

- Ao Prof. Dr. José Holanda Campelo Júnior, a orientação recebida;

- Aos Profs. Drs. Antonio Roberto Pereira, Luiz Roberto Angelocci e Nilson Augusto Villa Nova, pela fundamentação teórica recebida;

- Aos técnicos em Meteorologia Milton Bosco Guimarães, Victor Avalos Maciel e Ricardo Havvage Wolf da Estação Agrometeorológica Padre Ricardo Remetter, pelo apoio durante longos meses;

- Ao prof. Dr. Nicolau Priante Filho, pelo suporte técnico;

- Ao Núcleo de Tecnologia de Armazenagem e Curso de Pós Graduação em Agricultura Tropical da Universidade Federal de Mato Grosso, por cederem os intrumentos utilizados no experimento;

- Ao Departamento de Física da Universidade Federal de Mato Grosso; que concedeu-me o afastamento para a realização do Curso de Mestrado;

- Ao CNPQ, pela bolsa concedida;

- A Marlene, Gustavo e Mônica, minha família. 


\section{SUMÁRIO}

LISTA DE FIGURAS............................................................

LISTA DE TABELAS .......................................................... vii

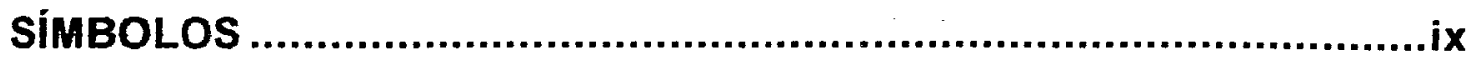

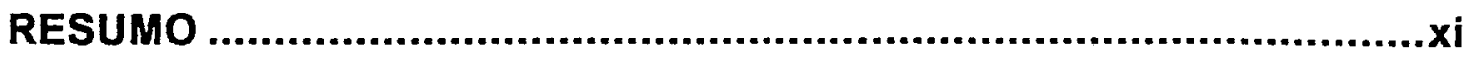

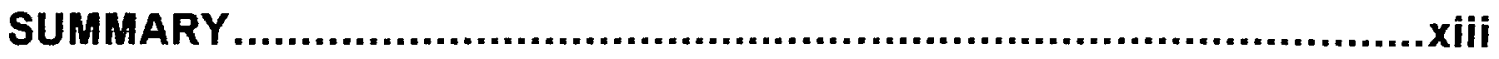

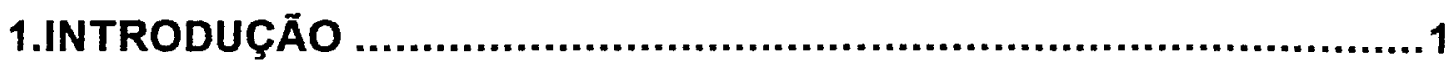

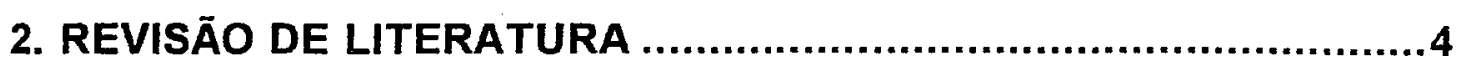

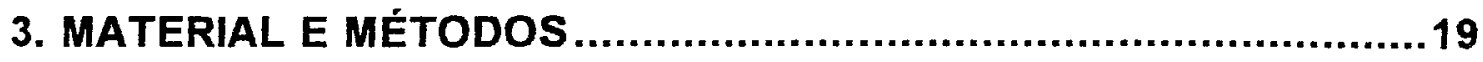

4. RESULTADOS E DISCUSSÃO ...........................................23

4.1. Balanço de Radiaçāo ..................................................23

4.2. Emissividade Média Diária ..........................................26

4.3. Emissividade Diurna ....................................................41

4.4. Emissividade Noturna .................................................46

4.5. Correção para a Presença de Nuvens ..............................54

5. CONCLUSÕES.............................................................. 56

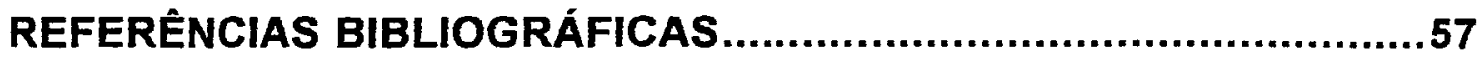




\section{LISTA DE FIGURAS}

a 1 - Valores instantâneos medidos da radiação global incidente (Rsg), radiação de ondas curtas, refletida (Rsr) e radiação liquida (Rn), nos dias 12/07/1994 e 13/07/1994, em Santo Antônio do Leverger.

a 2 - Valores instantâneos medidos da radiação global incidente (Rsg), radiação de ondas curtas refletida (Rsr) e radiação liquida (Rn), nos dias 03/09/1994 e 04/09/1994, em Santo Antônio do Leverger.

a 3 - Valores instantâneos medidos da radiação global incidente (Rsg), radiação de ondas curtas refletida (Rsr) e radiação liquida (Rn), nos dias 10/09/1994 e 11/09/1994, em Santo Antônio do Leverger. 29

a 4 - Valores instantâneos medidos da radiação global incidente (Rsg), radiação de ondas curta refletida (Rsr) e radiação líquida ( $R n)$, nos dias 17/09/1994, 18/09/1994 e 22/09/1994, em Santo Antônio do Leverger.

a 5 - Albedo da grama ao longo dos dias 11/07/1994 e 12/07/1994,em

Santo Antônio do Leverger.

a 6 - Albedo da grama ao longo dos dias 03/09/1994 e 04/09/1994, em

Santo Antônio do Leverger.

э 7 - Albedo da grama ao longo dos dias 10/09/1994 e 11/09/1994, em Santo Antônio do Leverger. 
a 8 - Albedo da grama ao longo dos dias 17/09/1994, 18/09/1994 e 22/09/1994, em Santo Antônio do Leverger.

a 9 - Valores instantâneos medidos da radiação global incidente (Rsg), radiação de ondas curtas refletida (Rsr), radiação liquida ( $R n)$ e balanço de radiaçäo de ondas longas $(\mathrm{Rb})$, no dia 02/09/1994, em Santo Antônio do Leverger.

a 10 - Emissividades diárias estimadas pelo método do balanço de radiação a partir dos dados deste trabalho e pelos modelos propostos por BRUNT (1932), SWINBANK (1963), IDSO \& JACKSON(1969) e BRUTSAERT(1975).

a 11 - Ajuste dos modelos de BRUNT (1932), SWINBANK (1963), IDSO \& JACKSON(1969) e BRUTSAERT(1975), dados diários.

a 12 - Emissividades diurnas estimadas pelos métodos do balançode radiação a partir dos dados deste trabalho e pelos modelos propostos por BRUNT (1932), SWINBANK (1963), IDSO \& JACKSON(1969) e BRUTSAERT(1975).

a 13 - Ajuste dos modelos de BRUNT (1932), SWINBANK (1963), IDSO \& JACKSON(1969) e BRUTSAERT(1975), dados diurnos.

a 14- Emissividades de dados noturnos estimados pelo balanço de radiação a partir dos dados deste trabalho e pelos modelos propostos por BRUNT (1932), SWINBANK (1963), IDSO \& JACKSON(1969) e BRUTSAERT(1975). 50

a 15 - Ajuste dos modelos de BRUNT (1932), SWINBANK (1963), IDSO \& JACKSON(1969) e BRUTSAERT(1975), dados noturnos. 
vii.

\section{LISTA DE TABELAS}

łla 1 - Valores médios diários de temperatura, pressão de vapor, balanço de ondas longas, teor de $\mathrm{CO} 2$ e emissividade.

əla 2 - Emissividade média diária estimada por equações empíricas. 36

zla 3 - Coeficientes de determinação entre a emissividade média diária estimada por equaçōes empíricas e a obtida através do balanço de radiação.

əla 4 - Emissividade média diurna estimada por equações empíricas.

əla 5 - Coeficientes de determinação entre a emissividade média diurna estimada por equaçōes empiricas e a obtida através do balanço de radiação.

əla 6 - Radiação efetiva de ondas longas $(R b)$, Temperatura $(T)$, pressäo de vapor atual (e), noturnos instantâneos, entre 20 e 21 horas, medidos em Santo Antônio do Leverger, em 1994 (julho, agosto e setembro)

zla 7 - Emissividade média noturna estimada por equações empíricas.

sla 8 - Coeficientes de determinação entre a emissividade média noturna estimada por equaçōes empíricas e a obtida através do balanço de radiação. 
ela 9 - Emissividade média diurna estimada por equações empiricas. ............. 52 ela 10 - Razão entre a radiação global incidente e a radiação extraterrestre

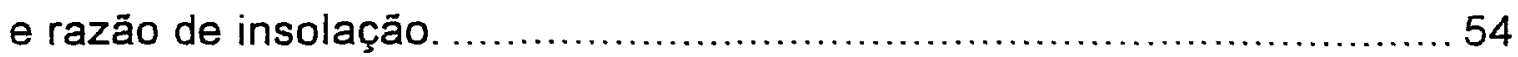

ela 11 - Coeficientes de determinação entre a emissividade obtida através do balanço de radiação e a emissividade média diária estimada por equações empíricas utilizando as relações de correção. 


\section{LISTA DE SIMBOLOS}

$a=$ Coeficiente de intersecção de retas de regressão.

$\mathbf{b}=$ Coeficiente de inclinação de retas de regressão.

$c=$ Coeficiente do termo de segunda ordem de retas de regressão.

$\mathrm{CO}_{2}=$ Teor de $\mathrm{CO}_{2}$ ao nível de abrigo.

$\mathbf{d}_{\mathbf{r}}=$ Distância relativa Terra-Sol .

$\mathbf{e}=$ Pressão de vapor

$\mathbf{f}=$ Fator de correção.

$f_{d w}=$ Fluxo de radiação devido ao vapor de água na atmosfera

$f_{\mathbf{c o} 2}=$ Fluxo de radiação devido ao $\mathrm{CO}_{2}$.

$f_{03}=$ Fluxo de radiação devido ao ozônio.

$f_{W ; c o 2}=$ Fluxo de radiação devido aos fluxos de água e $\mathrm{CO}_{2}$ superpostos.

$f_{2}=$ Constante.

$g_{2}=$ Constante.

$\mathbf{H}=$ Hora.

$\mathrm{J}=$ Número do dia Juliano.

$\mathbf{m}=$ Caminho ótico .

$\mathbf{n}=$ Horas de Britho Solar.

$\mathbf{N}=$ Duração do dia.

$p=$ Pressão atmosférica . 
$r=$ Coeficiente de correlação.

$\mathbf{R}_{\mathbf{g}}=$ Radiação extraterrestre

$\mathbf{R}_{\mathbf{a l}}$ = Radiação de ondas longas emitida pela atmosfera.

$\mathbf{R}_{\mathbf{s g}}=$ Radiação global incidente .

$\mathbf{R}_{\mathbf{S r}}=$ Radiação de ondas curtas refletida.

$\mathbf{R}_{\mathbf{n}}=$ Radiação líquida

$\mathbf{R}_{\mathbf{n s}}=$ Balanço de radiação de ondas curtas .

$\mathbf{R}_{\mathbf{b}}=$ Balanço de radiação de ondas longas ou emissão terrestre efetiva .

$\mathbf{R}^{\mathbf{2}}=$ Coeficiente de determinação.

$\mathbf{t}=$ Estatística de Student.

$\mathbf{T}=$ Temperatura .

$\mathbf{T}_{\mathbf{u}}=$ Temperatura de bulbo úmido.

UR = Umidade relativa .

$\alpha=$ Albedo.

$\gamma=$ Constante psicrométrica.

$\delta=$. Declinação solar.

$\varepsilon_{\mathbf{a}}=$ Emissividade da atmosfera com céu sem nuvens.

$\phi=$ Latitude.

$\sigma=$ Constante de Stefan-Boltzman.

$\boldsymbol{\omega}_{\mathbf{s}}=$ Ângulo horário do por do Sol. 
$x i$.

\title{
ESTIMATIVA DA EMISSIVIDADE ATMOSFÉRICA EM SANTO ANTÔNIO DO LEVERGER - MT
}

\author{
Autor: ENICILDO DEL DUCCAS MENDONÇA \\ Orientador: PROF. DR. JOSÉ HOLANDA CAMPELO JÚNIOR
}

\section{RESUMO}

O presente trabalho teve como objetivo determinar a emissividade da atmosfera em dias sem nuvens, em Santo Antônio de Leverger - MT, na época seca do ano.

0 experimento foi realizado entre os meses de julho e setembro de 1994, através de medidas da radiação líquida em todos os comprimentos de ondas, da radição solar incidente e refletida no solo, insolação, temperatura, pressão de vapor d'água e do teor de $\mathrm{CO}_{2}$ do ar ao nível do abrigo meteorológico.

A emissividade da atmosfera em dias sem nuvens foi obtida através do balanço de radiação e comparada com as estimativas encontradas com as equações empíricas de BRUNT (1932), SWINBANK (1963), IDSO \& JACKSON (1969) e BRUTSAERT (1975), a fim de estabelecer os coeficientes locais. Foi utilizado o método de regressão múltipla para analisar a influência do teor do gás carbônico, razão de insolação e transmissividade atmosférica, sobre a emissividade. 
xii.

Não houve influência do horário de medição sobre a emissividade da atmosfera em dias sem nuvens obtida através do balanço de radiação.

Não houve influência do teor do gás carbônico, da razão de insolação e da transmissividade atmosférica sobre a emissividade.

Usando coeficientes locais, a emissividade estimada através dos modelos propostos por BRUNT (1932) e BRUTSAERT (1975) se mostrou mais ajustada aos resultados observados do que as estimativas obtidas pelas equações propostas por SWINBANK (1963) e IDSO \& JACKSON (1969).

Para valores médios diários, o uso de qualquer uma das equaçōes analisadas permite obter estimativas da radiação líquida com erros inferiores a $5 \%$, e, para efeitos práticos de estimativa da disponibilidade de energia radiante diária, qualquer uma das equações proporcionaria erros inferiores a $10 \%$ da emissão efetiva. 
xiii.

\title{
ATMOSPHERIC EMISSIVITY ESTIMATE IN SANTO ANTONIO DO LEVERGER - BRAZIL
}

\author{
Author: ENICILDO DEL DUCCAS MENDONÇA \\ Adviser: PROF. DR. JOSÉ HOLANDA CAMPELO JÚNIOR
}

SUMMARY

The objective of this work was to determine the emissivity of clear sky in the Santo Antônio de Leverger, state of Mato Grosso, Brazil, in the dry season.

The experiment was carried out in the period from july to september, 1994. Net radiation (all-lenght waves), the downward and upward solar radiation, insolation, temperature, water-vapor pressure and $\mathrm{CO}_{2}$ content of the air in the level of meteorological shelter were measured.

Values of emissivity of the clear sky was estimated from the radiation balance and they were comparated to those estimated from empirical equations proposed the by BRUNT (1932), BRUTSAERT (1975), SWINBANK (1963) and IDSO \& JACKSON (1969), in order to establish the local coefficients. Multiple linear regression were used to analise the influence of carbon dioxide gas content, insolation and atmospheric transmitance on the emissivity. 
xiv.

The time of measurement had no influence in the emissivity of clear sky estimate from the radiation balance.

The carbon dioxide gas content, insolation e transmitance did not influence the emissivity.

Using local coeficients, the estimate of the emissivity from the equations proposed by BRUNT (1932) and BRUTSAERT (1975) showed better results than the estimate obtained from the equations proposed by SWINBANK (1963) and IDSO \& JACKSON (1969).

The use of any of the equations obtained in this stduy allow estimates of the net radiation with errors lower than $5 \%$, for average daily values, and for practical estimates of the daily radiant energy availability, whichever of the equations provide errors lower than $10 \%$ of the effective emission. 


\section{INTRODUÇÃO}

O balanço de energia de uma superfície é fundamental para a caracterização do clima em várias escalas e permite estimar a evapotranspiração, que é um parâmetro do balanço hídrico de utilidade para a irrigação e o zoneamento agrícola.

Para determinar a evapotranspiração através dos métodos de balanço de energia é necessário determinar a radiação líquida, isto é, a soma do balanço de radiação de ondas curtas e ò de ondas longas.

A radiação líquida pode ser obtida através de medição direta do balanço de radiação ou da medição de seus componentes, utilizando radiômetros que normalmente não estão disponíveis em Estaçōes Meteorológicas e Agrometeorológicas, ou pode ser estimada através de parâmetros meteorológicos que permitam calcular os fluxos de energia radiante.

O balanço de radiação de ondas curtas é a diferença entre a radiação solar incidente e a radiação de ondas curtas refletida pela superfície. A primeira pode ser medida diretamente com solarimetros, ou estimada através do produto da radiação extraterrestre por um fator de correção do tipo equação de Angströn. A radiação solar refletida pode também ser medida diretamente, ou estimada a partir da radiação solar incidente e do albedo da superfície. 
A estimativa da radiação líquida de ondas longas pode ser realizada através da equação de Stefan-Boltzmann, da emissividade efetiva da atmosfera em dias sem nuvens, que é a diferença entre a emissividade da atmosfera e a da superficie, e de um fator de correção para a presença de nuvens, determinado através de medidas de insolação ou de nebulosidade.

A emissividade de uma superficie totalmente vegetada apresenta pouca variabilidade, estando seu valor compreendido entre 0,94 e 0,98 de acordo com a revisão realizada pela Food and Agriculture Organization of the United Nations (FAO) em 1991, entretanto, o valor mais utilizado para a emissividade da superficie, de acordo com a bibliografia pesquisada é 1 .

A emissividade da atmosfera em dias sem nuvens é um importante parâmetro para a estimativa do balanço de radiação e difícil de ser calculada com exatidão. Ela depende fundamentalmente das quantidades presentes na atmosfera de vapor d'água, gás carbônico, ozônio e aerossóis; dos quais o vapor d'água tem sido considerado o único a provocar alguma variabilidade substancial. Entretanto, em alguns casos torna-se necessário um estudo mais profundo da influência dos outros constituintes, visto que em determinadas regiōes que sofrem influências de atividades vulcânicas, em regiōes de novas fronteiras agrícolas, como no cerrado, e em regiōes onde é cultivada tradicionalmente a cana de açúcar, ou onde ocorrem constantes queimadas, o teor de $\mathrm{CO}_{2}$ atmosférico sofre um aumento, normalmente cíclico. 
A emissividade da atmosfera em dias sem nuvens pode ser determinada através de medidas de perfis de temperatura e de umidade, os quais raramente estão disponiveis, ou através de medidas, ao nível do abrigo meteorológico, de pressão atual de vapor d'água e/ou temperatura. As equações que relacionam essas grandezas são de natureza empirica e dependem de coeficientes obtidos localmente. Além disso, elas não levam em consideração explicitamente o teor de gás carbônico.

Em regiōes onde a oscilação do teor de gás carbônico é maior que o usual, ele pode ser introduzido como uma variável nas equações ou pode influenciar as constantes empíricas das equações de previsão da emissividade da atmosfera em dias sem nuvens.

Santo Antonio do Leverger é um município de Mato Grosso, situado na zona de transição entre o cerrado e o pantanal, a cerca de trinta quilômetros de Cuiabá. Está localizado em uma região que vem sendo ocupada de modo intensivo nos últimos anos e onde ainda são escassas as informações que caracterizem o meio físico, especialmente no que diz respeito aos efeitos do acúmulo de fumaça na época mais seca do ano (setembro).

O objetivo do presente trabalho foi determinar a emissividade da atmosfera em dias sem nuvens em Santo Antônio do Leverger, na época seca do ano. 


\section{REVISÃO DE LITERATURA}

BRUNT (1932) propôs que a emissividade da atmosfera em dias sem nuvens fosse determinada através da seguinte equação:

$$
\varepsilon_{a}=a+b \sqrt{e}
$$

onde e é a pressão parcial do vapor d'água. Ele estabeleceu os valores de $a=0,52$ e $b=0,065$, quando a pressāo parcial do vapor d'água é medida em mbar. Os valores da radiação de ondas longas incidente, utilizados por BRUNT (1932), foram médias mensais obtidas por Dines entre 1922 a 1926 em Benson (estação de baixa altitude), e as médias mensais da pressão de vapor foram obtidas em Kew (com a pressão de vapor variando entre 7,7 e 14,4 mbar). O coeficiente de correlação por ele obtido entre a emissividade da atmosfera em dias sem nuvens e a raiz quadrada da pressão de vapor d'água foi de 0,97 .

BRUNT (1932) analisou as seguintes séries de dados para validar a aplicabilidade de sua equação:

1- 28 dados de radiação líquida e de pressão de vapor d'água obtidos de Asklf em Upsala, em noites claras e em estação de baixa altitude, com a pressão de vapor d'água variando entre 2 e $8 \mathrm{mbar}$, obtendo $a=0,43$ e $b=0,082$, com $r=0,83$; 
2- 38 dados de Angström, em Bassour, a $1160 \mathrm{~m}$ de altitude, observados em noites claras, com a pressão de vapor d'água variando entre 5 e 15,3 mbar, obtendo $a=0,48$ e $b=0,058$, com $r=0,73$;

3- As observações de Boutaric, na França, em maio, junho, novembro e dezembro de 1914, em Montpellier, e em agosto de 1919, em Pic du Midi, a 2859m de altitude, com a pressão de vapor d'água variando entre 3 e 11 mbar, obtendo $a=0,60$ e $b=0,042$;

4- As 1350 observações efetuadas em Lindenberg e apresentadas por Robitsch com a pressão de vapor d'água variando entre 3 e 22 mbar, obtendo $a=0,34$ e $b=0,110$, com $r=1$;

5- Os valores de $a=0,47$ e $b=0,061$ com $r=0,92$ se ajustaram aos dados de Ramanathan e Desai, obtidos em Poona, com a pressão de vapor d'água variando entre 8 e 18 mbar;

Baseado em todos os dados anteriores, BRUNT (1952) apresentou os seguintes valores médios para os coeficientes: $a=0,44$ e $b=0,080$, com $r=0,92$; com a pressão de vapor em mbar.

Segundo BRUNT (1952), o valor da constante a não representa a emissividade do céu completamente seco como sugere a sua equação.

Sobre a variabilidade dos coeficientes apresentada nas séries de dados por ele analisada, BRUNT (1952) supôs que parte podia ser devido a diferença real no gradiente de temperatura e pressão de vapor d'água com a altura, mas que era mais provável que fosse devido a diferenças de métodos de observação.

BRUNT (1952), considerou as equaçōes tipo Brunt e Angströn como as melhores fórmulas empíricas, mas elas não 
6.

forneceram representação exata de observaçōes individuais. Acrescentou também que apesar das medidas de Dines terem sido realizadas principalmente à noite, os fluxos de radiação de ondas longas do dia não poderiam diferir do noturno em ordem de magnitude visto que o vapor d'água na atmosfera não muda diuturnamente.

De acordo com MONTEITH (1961) os valores de a e b obtidos por BRUNT (1932) na análise conjunta de vários locais estão distorcidos pelos dados anômalos de Robitzsch cuja técnica foi criticada por Raman (1953). MONTEITH (1961) propôs então, a partir da análise de 38 dados do Observatório de Kew, obtidos por Lönnqvist que:

$$
\varepsilon_{a}=0,70+0,22 \log (\mathrm{m})
$$

onde $\mathbf{m}$ é o caminho ótico.

Utilizando-se da equação de Belasco (1952):

$$
\log (m)=-0,80+0,29 \sqrt{e}
$$

obteve a seguinte equação:

$$
\varepsilon_{a}=0,53+0,065 \sqrt{e}
$$

que é praticamente a mesma que a de BRUNT (1932) para Benson.

MONTEITH (1961) considerou que as diferenças entre os coeficientes a e b encontrados por BRUNT (1932) eram devidas às diferenças na distribuição de vapor d'água atmosférico com a altura ou aos 
erros experimentais, e que essas equaçōes empíricas não poderiam ser utilizadas com a mesma confiabilidade em outros locais.

SWINBANK (1963) salientou que a influência da pressão de vapor d'água sobre a radiaçāo de ondas longas emitida pela atmosfera em dias sem nuvens era exagerada e que a emissividade da atmosfera em dias sem nuvens poderia ser obtida com alto grau de exatidão somente com a temperatura do ar ao nível do abrigo meteorológico.

De acordo com SWINBANK (1963) a variabilidade dos coeficientes $\boldsymbol{a}$ e $\boldsymbol{b}$ encontrada por BRUNT (1932) não deve ter sido devida a procedimentos experimentais, e sim porque a relação entre a emissividade e a umidade resulta basicamente do regime de temperatura-umidade local. Como BRUNT (1932) havia sugerido anteriormente, ele considerou que a pressão de vapor d'água, ao nível do abrigo, de algum modo era representativa da umidade e temperatura acima da estação, e então a distribuição vertical de temperatura deveria estar correlacionada com a raiz quadrada da pressão de vapor d’água. A não existência de diferenças em b devido a altitude, foi considerada significante, uma vez que a quantidade de vapor d'água varia com a altitude.

SWINBANK (1963) analisou as observaçōes de Dines para os meses de maio e setembro e verificou que elas apresentavam praticamente os mesmos valores de radiação de ondas longas incidente, apesar da troposfera ser mais quente e úmida em setembro. A pressão de vapor observada na superfície foi maior em setembro, enquanto que as temperaturas foram virtualmente as mesmas, sugerindo que dentro da 
8.

faixa de umidade que ocorrera na atmosfera, a emissividade da atmosfera em dias sem nuvens dependeria somente da temperatura. As diferenças entre os coeficientes $\mathbf{a}$ e $\mathbf{b}$ referentes aos dados de Dines $e$ Boutaric, que apresentam razoável homogeneidade, deveriam ser devidos aos regimes bastante diferentes de temperaturas.

Através da análise de 100 dados obtidos, a maioria em torno das 20 horas, em Aspendale e no Oceano Índico, com a temperatura variando entre 25,2 e $28,3^{\circ} \mathrm{C}$ e a pressão de vapor d'água entre 15,91 e 35,00 mbar, SWINBANK (1963) propôs a seguinte equação:

$$
\log \left(R_{a l}\right)=-13,638+6,148 \log (T)
$$

onde $\mathbf{R}_{\mathbf{a}}$ é a radiação de ondas longas emitida pela atmosfera, medida em $\mathbf{m W} / \mathrm{cm}^{2}$ e obteve $r=0,985$. Arredondado o coeficiente de $\log T$ para 6 obteve:

$$
\varepsilon_{a}=0,9210^{-5} \mathrm{~T}^{2}
$$

onde $\mathbf{T}$ é dado em Kelvin. A diferença em $\boldsymbol{R}_{\mathbf{a l}}$ estimado para uma temperatura de $300 \mathrm{~K}$ entre as duas expressões é de apenas 0,2 $\mathrm{mW} / \mathrm{cm}^{2}$ em $39 \mathrm{~mW} / \mathrm{cm}^{2}$.

Para os dados obtidos em Benson, SWINBANK (1963) determinou a seguinte equação:

$$
\varepsilon_{a}=0,9010^{-5} \mathrm{~T}^{2}
$$


com $r=0,989$ entre $\log R_{\mathrm{al}}$ e $\log \mathrm{T}$.

SWINBANK (1963) justificou a dependência da emissividade da atmosfera em dias sem nuvens com a temperatura pelo fato das parcelas da radiação reemitidas pelo vapor d'água e pelo dióxido de carbono originarem-se em niveis imediatamente acima da superfície, com temperaturas próximas à temperatura no nivel do abrigo meteorológico, logo podendo ser a radiação de ondas longas incidente definida em função somente dessa temperatura. Sugeriu ainda que, sendo a emissividade uma função primária do vapor d'água, se o conteúdo de água em algum nivel da atmosfera for bastante baixo para causar em $\mathbf{R}_{\mathbf{a}}$ uma queda além daquela indicada pela expressão por ele formulada, então devem ser realizadas novas pesquisas em altitudes maiores do que as até então realizadas.

IDSO \& JACKSON (1969) analisaram o espectro de emissão da água, a $273 \mathrm{~K}$, e consideraram que esse espectro representava a contribuição mínima do vapor d'água para a emissividade atmosférica. A partir dessa suposição eles calcularam a radiação emitida pelo vapor d'água, à temperatura do abrigo, que foi por eles denominada de radiação atmosférica mínima calculada. Entretanto essa radiação atmosférica minima calculada poderia ser ainda menor, visto que quando a temperatura cai, parte do vapor d'água é retirado da atmosfera. Mas, normalmente, ao atingir uma temperatura de $273 \mathrm{~K}$ parte do vapor d'água cristaliza-se antes que possa ser retirado, e sendo o gelo considerado como um corpo negro, para comprimentos de onda acima de $1 \mu \mathrm{m}$, a radiação emitida pela atmosfera voltaria a aumentar. Assim sendo, a radiação emitida pela atmosfera deveria estar compreendida entre a 
radiação atmosférica mínima calculada e a radiação do corpo negro, para a temperatura do abrigo, que é um valor que não poderia ser ultrapassado.

IDSO \& JACKSON (1969) observaram que os dados de radiação atmosférica obtidos por SWINBANK (1963) estavam entre os obtidos através da radiação atmosférica mínima calculada e a radiação do corpo negro. Ao traçarem a curva da eq. 5, de SWINBANK (1963), observaram que ela não passava pela origem. Eles propuseram uma nova equação, considerando válida a equação de MONTEITH (1961) (eq. 2) e associando a ela a equação abaixo, de Osborne-Meyers como citada por Dorsey (1940), para estimar a pressão de vapor atual:

$$
e=6,11 \exp \left[\left(16,9\left(1-\frac{273}{T}\right)\right]\right.
$$

obtiveram:

$$
\varepsilon_{a}=0,527+0,161 \exp \left[8,45\left(1-\frac{273}{T}\right)\right]
$$

com e e $\mathrm{T}$ dados respectivamente em mbar e $\mathrm{K}$.

Analisando a eq. 9, IDSO \& JACKSON (1969), verificaram que a emissividade calculada por essa equação poderia ser maior que 1 ou menor que a emissividade atmosférica mínima calculada. Em vista disso, propuseram que uma fórmula do tipo:

$$
\varepsilon_{a}=1-c \exp \left[-d(273-T)^{2}\right]
$$


deveria ajustar-se aos dados, pois o 1 garantiria que a radiação do corpo negro não seria ultrapassada e o quadrado garantiria a simetria em torno de $273 \mathrm{~K}$, conforme dados da época indicavam.

Aos dados de SWINBANK (1963), IDSO \& JACKSON (1969) acrescentaram dados de baixa temperatura obtidos perto de Point Barrow, no Alaska, por Lieske e Stroschein (1968) e de altas temperaturas dos registros da U.S. Water Conservation Laboratory em Phoenix, no Arizona, determinando assim os valores das constantes da eq. 10, e finalmente apresentaram a seguinte equação:

$$
\varepsilon_{a}=1-0,261 \exp \left[-7,7710^{-4}(273-T)^{2}\right]
$$

com $r=0,992$.

IDSO \& JACKSON (1969) afirmaram que essa equação seria válida para qualquer latitude e temperatura alcançada na Terra.

Os 6 pontos de baixa temperatura do Alaska utilizados por IDSO \& JACKSON (1969) representavam médias de 830 meia-horas e foram obtidos com um radiômetro tipo FUNK CSIRO (o mesmo que Swinbank utilizou). As medidas de Phoenix foram obtidas com um radiômetro líquido de Fritschen (1963) e a radiação solar direta e difusa com solarímetros Kipp-Zonen (direto e invertido). Algumas dessas medidas foram diurnas.

BRUTSAERT (1975) derivou uma equação para predizer a .. emissividade da atmosfera em dias sem nuvens em condições atmosféricas próximas à atmosfera padrão, através da integração da equação de Schwarzschild, num cálculo análogo aos de cartas de fluxo, mas 
12.

utilizando certas simplificaçōes. A simplificação fundamental foi assumir uma função de fonte isotrópica em uma atmosfera estratificada para a qual os coeficientes de absorção e temperatura dependeriam somente da elevação. Os gradientes de temperatura, pressão atmosférica, pressão e densidade de vapor d'água seriam exponenciais. A equação por ele encontrada foi:

$$
\varepsilon_{a}=1,24\left(\frac{e}{T}\right)^{\frac{1}{7}}
$$

com e dado em mbar e $\mathrm{T}$ em $\mathrm{K}$.

Ele assumiu uma temperatura típica de abrigo de $288 \mathrm{~K} \mathrm{e}$ por ser a eq. 12 muito insensivel a mudanças da temperatura, então propôs:

$$
\varepsilon_{a}=0,553 \mathrm{e}^{\frac{1}{7}}
$$

BRUTSAERT (1975) afirmou que a equação de Swinbank poderia ser justificada teoricamente considerando-se que as médias mensais por ele obtidas cobriam uma faixa climática em que a quantidade de água precipitável era proporcional à potência 16.8 da temperatura ao nivel do abrigo.

AASE \& IDSO (1978) compararam a radiação de ondas longas incidente medida com a obtida a partir das equaçōes de Idso \& Jackson (eq. 11) e de Brutasaert (eq. 12) com temperaturas medidas em Sidney, Montana ( 47 graus 45 minutos $N$ e 104 graus e 10 minutos 0 ), as quais variaram entre -37 e $36 \mathrm{C}$ (médias diárias entre -30.3 e $26.9^{\circ} \mathrm{C}$ ) 
medidas com termômetros aspirados, ao nivel de abrigo, enquanto as médias de pressão de vapor (médias diárias entre 0,6 e 18,4 mbar) foram obtidas a partir de termohigrógrafo no mesmo nivel. Foram calculadas as médias entre a temperatura máxima e mínima diária, e a pressão de vapor média diária foi calculada pela equação de Tetens:

$$
e=6,11 \text { UR } 10^{\frac{7,5 T}{T+237,3}}
$$

onde $\mathbf{T}$ é a temperatura média diária em Celsius e UR é a umidade relativa diária média (12 valores horários/12). A radiação de ondas longas incidente foi obtida pela subtração da radiação de ondas curtas incidente, medida com um pirânometro Eppley de temperatura compensada, e o balanço de radiação medido com um radiômetro de dois hemisférios conforme descrito por Idso (1971). Os valores médios diários variaram entre 259 a 821 Ly/dia e todos os dados analisados eram diurnos, com céu claro (Radiação Solar $\geq 90 \%$ do possivel). Acima de $0^{\circ} \mathrm{C}$ ambas as equações estimaram bem a radiação de ondas longas incidente em condiçöes de céu sem nuvens, entretanto abaixo $0^{\circ} \mathrm{C}$, a equação baseada no modelo de Brutsaert subestimou a emissividade de céu claro, enquanto a baseada no modelo de Idso \& Jackson subestimou levemente no inicio e passou a superestimar quando a temperatura caiu para $-37^{\circ} \mathrm{C}$. Em relação à equação baseada no modelo de Brutsaert o resultado era esperado, pois foi derivada para atmosfera padrão (e não para temperaturas negativas). Para a equação baseada no modelo de Idso \& Jackson, a qual foi derivada tanto para temperaturas negativas como para temperaturas positivas houve uma super 
compensação das correções por eles adotada, na faixa de temperaturas negativas.

Os desvios encontrados foram explicados em termos do "broad minimum" apresentado pela emissividade da atmosfera em dias sem nuvens centrada em $0^{\circ} \mathrm{C}$, quando a temperatura diminue além de $0^{\circ}$ C a emissividade da atmosfera inicialmente aumenta, do mesmo modo que quando a temperatura aumenta a partir de $0^{\circ} \mathrm{C}$. Concluíram sugerindo novas pesquisas para corrigir os desvios em temperaturas negativas. HATFIELD et al (1983) a partir de dados obtidos em quinze localidades, durante os verōes de 1979,1980 e 1981; no meio oeste americano na faixa de latitude $26^{\circ} 13^{\prime} \mathrm{N}$ a $47^{\circ} 46^{\prime} \mathrm{N}$ e longitude $96^{\circ} 11^{\prime}$ a $121^{\circ} 45^{\prime}$ e altitudes entre -30 a $3342 \mathrm{~m}$, compararam diversas equações de estimativas de radiação de ondas longas incidente. As temperaturas de bulbo seco foram medidas com um termômetro de resistência de platina e a temperatura de ponto de orvalho com um higrômetro de platina de exatidão de $0,5^{\circ} \mathrm{C}$. As medidas, com amostragens de 1 minuto e média horária, foram realizadas a uma altura de 4,5 $\mathrm{m}$. A radiação de ondas longas incidente foi medida a $2,5 \mathrm{~m}$ de altura, com amostragem de 1 minuto e integrada trapezoidalmente para obter média horária, somente em noites claras para evitar interferência da radiaçāo solar.

Quando se efetua a medida independente de cada um dos fluxos envolvidos no balanço de radiação, pode haver diferenças entre os resultados obtidos através de medidas diretas e os obtidos através das medidas dos componentes do balanço (DUCHON e WILK, 1994). Além disso, há registro da ocorrência de erros de medida da radiação de 
onda longa, provocados pela incidência de ondas curtas sobre os sensores (CULF \& GASH, 1993).

Os resultados dos estudos de HATFIELD et al (1983), onde a faixa de radiação de ondas longas medidas foi de 947 a 1530 $\mathrm{kJ} /\left(\mathrm{m}^{2} \mathrm{~h}\right)$, mostraram que as equações baseadas na estimativa da emissividade da atmosfera, em dias sem nuvens, a partir da pressão de vapor (Brunt e Brutsaert) foram mais adequadas que as baseadas em temperaturas (Swinbank e Idso \& Jackson) e que estas não eram adequadas para estimar os fluxos de ondas longas sobre amplas áreas geográficas.

VISWANADHAM \& MASCARENHAS (1978) apresentaram - fluxo de radiação de ondas longas incidente, como uma superposição de fluxos fundamentais, assim descrito:

$$
R_{\mathrm{al}}=\mathbf{f}_{\mathrm{dW}}+\mathbf{f}_{\mathrm{CO}_{2}}+\mathbf{f}_{\mathrm{O}_{3}}-\mathbf{f}_{\mathrm{W}_{1} \mathrm{CO}_{2}}
$$

onde $f_{d w}$ é o fluxo devido ao vapor d'água na atmosfera, $f_{\mathbf{c o 2}}$ devido ao $\mathrm{CO}_{2}, \mathrm{f}_{\mathrm{O} 3}$ ao ozônio (o qual por ser muito pequeno, em relação ao fluxo devido ao vapor d'água, pode ser desprezado) e $f_{\mathbf{w} ; c 02}$ é devido aos fluxos de água e $\mathrm{CO}_{2}$ superpostos.

STALEY \& JURICA (1972) propuseram que o fluxo gerado pelo $\mathrm{CO}_{2}$ e o fluxo radiante devido à superposição poderiam ser estimados através da Lei de Stefan \& Boltzman, do seguinte modo:

$$
f_{\mathrm{CO}_{2}}=f_{2} \sigma T^{4}
$$




$$
f_{w ; c_{2}}=g_{2} \sigma T^{4}
$$

Considerando que para CNTP o teor de $\mathrm{CO}_{2}$ era de $3,14 \mathrm{x}$ $10^{-3} \mathrm{~cm}$ de profundidade ótica, utilizando dados climáticos de temperatura e pressão na faixa de 0 a10 $\mathrm{N}$, (LONDON, 1952), e baseando-se nas cartas de Elsasser e Culbertson (1960), VISWANADHAM \& MASCARENHAS (1978) estimaram os valores dos parâmetros das equações 16 e 17 como 0,1694 e 0,011 , respectivamente. Além disso, utilizando-se das eq. 15, 16 e 17, dados de rádio-sondagens, dados de temperatura e pressão de vapor obtidas a bordo dos navios N. Hi. Sírius e Almirante Saldanha, durante o GARP Atlantic Tropical Experiment (GATE), de julho a setembro de 1974, e das cartas de Elsasser obtiveram os seguintes valores para os parâmetros da equação de BRUNT (1932): $\mathbf{a}=0,705$ a 0,721 e $\mathbf{b}=0,021$; mas não conseguiram estabelecer relações de dependência da radiação de ondas longas com quadrado da temperatura conforme proposto por SWINBANK (1963).

Segundo VISWANADHAM \& MASCARENHAS (1978), Deacon (1970) encontrou dependência do parâmetro b com a altura. Quanto mais elevada o nível da estação maior seria o valor de b.

VISWANADHAM \& MASCARENHAS (1978) afirmaram que a variabilidade dos parâmetros da equação de Brunt estava relacionada com variações de altitude, latitude e com diferenças de distribuição de temperatura e umidade. Em situações de fortes inversões térmicas, próximas à superfície, não se deveria esperar que o fluxo de radiação de ondas longas incidente fosse descrito por funções simples da 
temperatura e umidade, pois o decréscimo da temperatura e da umidade com a altura poderia não ser regular e uniforme, e ressaltaram que até aquela data, aparentemente, o assunto nāo fora investigado.

Em pesquisa anterior, VISWANADHAM (1978), afirmou que a ocorrência de gradiente de temperatura positivo juntamente com névoa diminuia moderadamente a radiação de ondas longas ascendente, enquanto a radiação de ondas longas incidente aumentava.

PAVÃO \& SOUZA (1995) estudando a influência das queimadas no teor de $\mathrm{CO}_{2}$ em Cuiabá-Mt através de um analisador infravermelho não dispersivo, instalado nas dependências do INPE (Instituto Nacional de Pesquisas Espaciais) nas proximidades da zona urbana, obtiveram que para os anos de 1991 e 1992 os teores médios de $\mathrm{CO}_{2}$ nos meses de setembro e novembro foram de 371 ppmv e 350 ppmv respectivamente. Outro aspecto observado por estes autores foi a existência de uma alta concentração de $\mathrm{CO}_{2}$ no período de queimadas e baixa concentração no periodo de chuvas.

A despeito dos avanços que têm ocorrido na tecnologia de medida da radiação, as dificuldades técnicas e o custo dos equipamentos, aliados à variabilidade espacial, são responsáveis pelo considerável interesse que ainda há em determinar a radiação incidente de onda longa em função de parâmetros meteorológicos de superfície. Ainda mais que o uso das equações empíricas de estimativa tem sido estendido para intervalos horários, em dias sem nuvens (HATIFIELD et al.,1983; e DAUGHTRY et al., 1990), ou mesmo com a presença de nuvens (SUGITA e BRUTSAERT, 1993), embora o efeito das nuvens possa variar de acordo com a sua localização (BLISS, 1961). 
18.

Atualmente, apesar da preocupação crescente com as consequências que poderiam advir do eventual aumento da emissão de radiação da atmosfera (INTERGOVERNAMENTAL PANEL ON CLIMATE CHANGE - 1990), vários autores permanecem utilizando o cálculo da emissividade atmosférica proposto por BRUNT (1932), indiferentemente do local (URIARTE, 1990; LEITE et alli, 1990; FAO, 1991), desconsiderando inclusive os trabalhos de MONTEITH (1961), SWINBANK (1963), IDSO \& JACKSON (1969) e BRUTSAERT (1975). 


\section{MATERIAL E MÉTODOS}

O experimento foi realizado na Fazenda Experimental da Universidade Federal de Mato Grosso, na Estação Agrometeorológica Padre Ricardo Remetter, em Santo Antônio de Leverger, com latitude de $15^{\circ} 47^{\prime} 11^{\prime \prime S}$, longitude de $56^{\circ} 04^{\prime} 17^{\prime \prime} \mathrm{W}$ e altitude de $140 \mathrm{~m}$.

Foram utilizados os seguintes instrumentos:

1- Um radiômetro líquido Modelo 3032-A fabricado por Novalynx Corporation-Inglaterra com resistência nominal de 4 ohms, resposta espectral de 0.025 a $60 \mu \mathrm{m}$, constante de tempo de $10.5 \mathrm{~s}$ e fator de calibração nominal de $12.9 \mathrm{~W} /\left(\mathrm{m}^{2} \mathrm{~V}\right)$.

2- Dois solarímetros fabricado por PP Systems-Inglaterra, consistindo de termopilha de multi-junção de cobre-constatan com saida de $0-1 \mathrm{~V}$ correspondendo 0 a $1500 \mathrm{~W} / \mathrm{m}^{2}$.

3- Uma unidade analisadora e armazenadora de dados de dióxido de carbono EGM-1/WMA-2 com saída para os Solarímetros, cujo método de medida do gás é por infravermelho não dispersivo, com micro processador de controle, com faixa de medida de 0-2000 ppmv de gás carbônico por volume e precisão e linearidade de $1,0 \%$ do fundo de escala.

4- Um termohigrógrafo, marca This pertencente à Estação Agrometeorológica de Santo Antônio de Leverger. 
5- Um heliógrafo, tipo Campbel, pertencente à Estação Agrometeorológica de Santo Antônio de Leverger.

6- Termopares cobre constantan, $n^{\circ} 26$ para a determinação da temperatura de bulbo seco e de bulbo úmido com abrigos meteorológicos construídos de tubo de PVC

7- Um anemômetro fabricado pela Vector Instruments, modelo A100R, tipo três conchas, com ressalto livre, com velocidade mínima de $0,2 \mathrm{~m} / \mathrm{s}$ e velocidade máxima superior a $75 \mathrm{~m} / \mathrm{s}$, e com exatidão de $1 \%$.

8- Um barômetro, pertencente à Estação Agrometeorológica de Santo Antônio de Leverger.

Os solarímetros e o radiômetro liquido foram colocados no nivel de $0.70 \mathrm{~m}$, os termopares no nivel de $1,5 \mathrm{~m}$ e o termohigrógrafo e a unidade EGM-1 no abrigo meteorológico da Estação no nível de 1,5m.

Foram realizadas 700 observações de meia em meia hora, ao longo de 25 dias no período compreendido entre os dias 11 de julho e 22 de setembro de 1994.

O balanço de radiação de ondas longas $\left(R_{b}\right)$ foi obtido através de medidas de radiação líquida $\left(R_{n}\right)$, radiação solar incidente $\left(R_{s g}\right)$ e refletida $\left(R_{S r}\right)$, isto é:

$$
R_{b}=R_{n}-R_{s g}-R_{s r}
$$

A emissividade da atmosfera em dias sem nuvens foi estimada por: 


$$
\varepsilon_{a}=1+\frac{R_{b}}{\sigma T^{4}}
$$

A duração do dia foi calculada por:

$$
\mathrm{N}=\frac{24}{\pi} \omega_{\mathrm{s}}+0,11
$$

onde o ângulo horário do por do sol foi obtido por:

$$
\omega_{s}=\arccos (-\tan \phi \tan \delta)
$$

e a declinação solar:

$$
\delta=0,4093 \operatorname{sen}(0,0172 \mathrm{~J}-1,405)
$$

sendo $\mathrm{J}$ o número do dia Juliano.

A radiação extraterrestre foi calculada por:

$$
R_{a}=1440 \frac{G_{s C}}{\pi} d_{r}\left\langle\omega_{s} \operatorname{sen} \phi \operatorname{sen} \delta+\cos \phi \cos \delta \cos \omega_{s}\right\rangle
$$

onde a constante solar é igual a $G_{S C}=1367 \mathrm{~W} / \mathrm{m}^{2}(F A O, 1991)$.

A distância relativa Terra-Sol foi calculada por:

$$
d_{r}=1+0,033 \operatorname{sen}\left(\frac{2 \pi}{365} J\right)
$$


Os valores da pressão do vapor d'água média, em mbar, foram calculadas a partir dos valores estimados a cada 30 minutos da pressão de vapor pela equação recomendada pela FAO (1991):

$$
e=6,108 \exp \left(\frac{17,27 T_{u}}{237,3+T_{u}}\right)-\gamma p\left(T-T_{u}\right)
$$

onde $\gamma$ foi de 0,0012 para a velocidade do vento até $1 \mathrm{~m} / \mathrm{s}$ e de 0,00066 para velocidades do vento superior a $1 \mathrm{~m} / \mathrm{s}, T_{\mathbf{u}}$ foi a temperatura de bulbo úmido e $\mathbf{p}$ foi a pressão atmosférica.

Os solarimetros foram comparados entre si e também com um actinógrafo, com apenas algumas horas de uso, pertencente à Estação Agrometeorológica de Santo Antônio de Leverger; tendo sido realizadas as correções necessárias. 
23.

\section{RESULTADOS E DISCUSSÃO}

\subsection{Balanço de Radiação}

As Figuras 1, 2, 3 e 4 mostram o comportamento das medidas instantâneas de radiação efetuadas em quatro seqüências de dias limpos utilizadas no presente trabalho.

A radiação global incidente apresentou crescimento no período matutino, seguido do decréscimo vespertino, numa variação regular, em obediência à lei de Lambert. Este comportamento foi interrompido apenas em alguns momentos, principalmente nos dias 11 , 17 e 22 de setembro, em virtude da passagem de algumas nuvens. Os valores obtidos foram inferiores aos encontrados na literatura para alturas do sol equivalentes em dias em dias sem nuvens (MONTEITH, 1965; De WIT, 1966; e ROSENBERG et al. ,1983). Embora haja registro que a transmitância em dias sem nuvens possa chegar a $80 \%$, em média, a transmitância atmosférica foi de $43 \%$, em conseqüência da presença de névoa seca.

A Massa Tropical Maritima, que é caracterizada por forte subsidência, predomina sobre a região nessa época do ano, dificultando a dispersão da névoa seca, especialmente a fumaça das queimadas 
(NIMER, 1979). Essas queimadas têm sido praticadas comumente no local, após o desbravamento do cerrado ou no manejo de pastagens.

A radiação refletida de onda curta também variou com o ângulo de incidência da radiação, obtendo-se os menores valores de albedo ao meio-dia (Figuras 5, 6, 7 e 8), conforme reportado por outros autores (MONTEITH, 1965 e ROSENBERG et al, 1983). Os valores médios diários de albedo foram aproximadamente iguais aos apresentados por DOORENBOS e PRUITT (1976); DOORENBOS e KASSAN (1979) e por ALLEN et al, (1989).

0 balanço de radiação teve resultado negativo e praticamente constante durante os periodos noturnos e foi influenciado de modo marcante pelo balanço de ondas curtas durante o período diurno, apresentando saldo positivo a cada periodo de 24 horas, conforme o esperado para um dia sem nuvens, mesmo no inverno, na região tropical, em conseqüência das posições relativas da Terra e do Sol.

Para se obter a emissividade atmosférica foi inicialmente necessário se determinar, de modo indireto, o balanço de radiação de ondas longas ou emissão terrestre efetiva $\left(R_{b}\right)$, através dos outros componentes do balanço de radiação, de acordo com a equação 19.

Os resultados obtidos mostraram que os valores de $R_{b}$ durante a noite foram semelhantes aos valores do período diurno entre as dez e as quatorze horas. Os outros valores de $R_{b}$ obtidos após o amanhecer e antes do pôr do sol se aproximaram de zero. Nesses períodos, os valores de $\mathrm{Rb}$ provavelmente superestimaram o balanço de ondas longas em conseqüência dos erros provenientes da alteração de 
sensibilidade do radiômetro líquido, provocada pela incidência de radiação solar. HALLDIN \& LINDROTH (1992), FIELD et al. (1992), CULF \& GASH (1993) e DUCHON \& WILK (1994) concluíram que a sensibilidade dos radiômetros líquidos é menor na faixa de ondas longas do que na faixa de ondas curtas.

Nos dias limpos, em virtude dos maiores valores do ângulo zenital nesses períodos do amanhecer e da tarde, a radiação incidente foi inferior a $500 \mathrm{~W} / \mathrm{m}^{2}$ e ocorreram os maiores valores de albedo ou, em termos absolutos, o balanço de radiação de ondas curtas assumiu valores da mesma ordem ou inferiores aọ da radiação liquida, que inclusive pode ter sido nulo. Nessas circunstâncias, o valor relativo dos erros de medida foi alto, inutilizando as medidas indiretas de $\mathrm{Rb}$.

Situação semelhante ocorreu com o balanço de radiação ao longo do dia 02/09/94 (Figura 9), que foi um dia inteiramente nublado e chuvoso. A radiação solar foi predominantemente difusa, e a insolação, de duas horas de brilho solar, se concentrou no final da tarde.

Conseqüentemente, a radiação incidente de ondas curtas se manteve abaixo de $350 \mathrm{~W} / \mathrm{m}^{2}$. Durante a manhã a radiação líquida foi igual ao balanço de radiação de ondas curtas, tornando-se ligeiramente inferior durante à tarde. No periodo diurno, os valores de $R_{b}$ obtidos de modo indireto foram desconsiderados porque foram todos positivos, enquanto que as medidas noturnas se mostraram consistentes com a existência da "janela atmosférica".

Convém salientar que a hipótese de reduzir a constante de calibração do radiômetro líquido indiscriminadamente para as medidas diurnas e noturnas foi descartada a priori, considerando que a 
emissão efetiva terrestre em dias sem nuvens poderia se tornar excessivamente baixa durante a noite e excessivamente alta ao meiodia.

Em vista do exposto, as análises do presente trabalho não contemplaram as emissividades correspondentes aos valores de $R_{b}$ superiores ao maior valor da madrugada do mesmo dia, sendo descartadas as medidas de início da manhã e do final da tarde dos dias limpos.

\subsection{Emissividade Média Diária}

Os valores utilizados para análise da emissividade média diária encontram-se na Tabela 1.

Através da Figura 10, que mostra os resultados da emissividade calculada pelas equações de BRUNT (1932), SWINBANK (1963), IDSO \& JACKSON (1969) e BRUTSAERT(1975), em comparação com a emissividade estimada através do balanço de radiação, pode-se verificar que, em geral, as equações originais testadas subestimaram a emissividade obtida indiretamente pelo balanço de radiação. Ao longo do tempo, todas as estimativas da emissividade permaneceram relativamente constantes, mas as médias das diferentes estimativas apresentaram diferenças significativas (teste $\mathbf{t}$ de Student para amostradas emparelhadas) em relação ao valor médio de 0,9026 , obtido por meio do balanço de radiação (Tabela 2). 


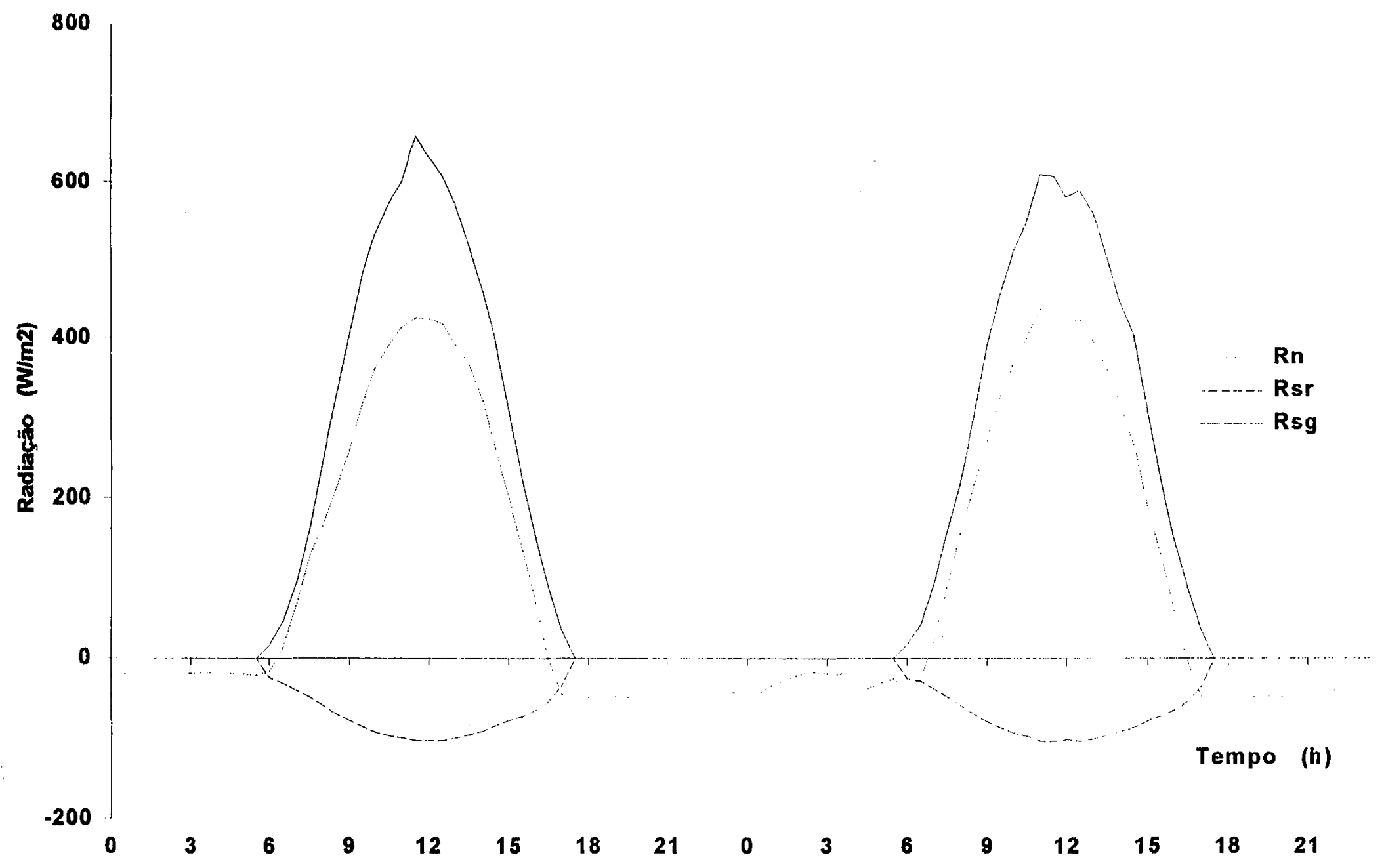

Figura 1 - Valores instantâneos medidos da radiação global incidente (Rsg), radiação de ondas curtas, refletida (Rsr) e radiação líquida (Rn), nos dias 12/07/1994 e 13/07/1994, em Santo Antônio do Leverger. 


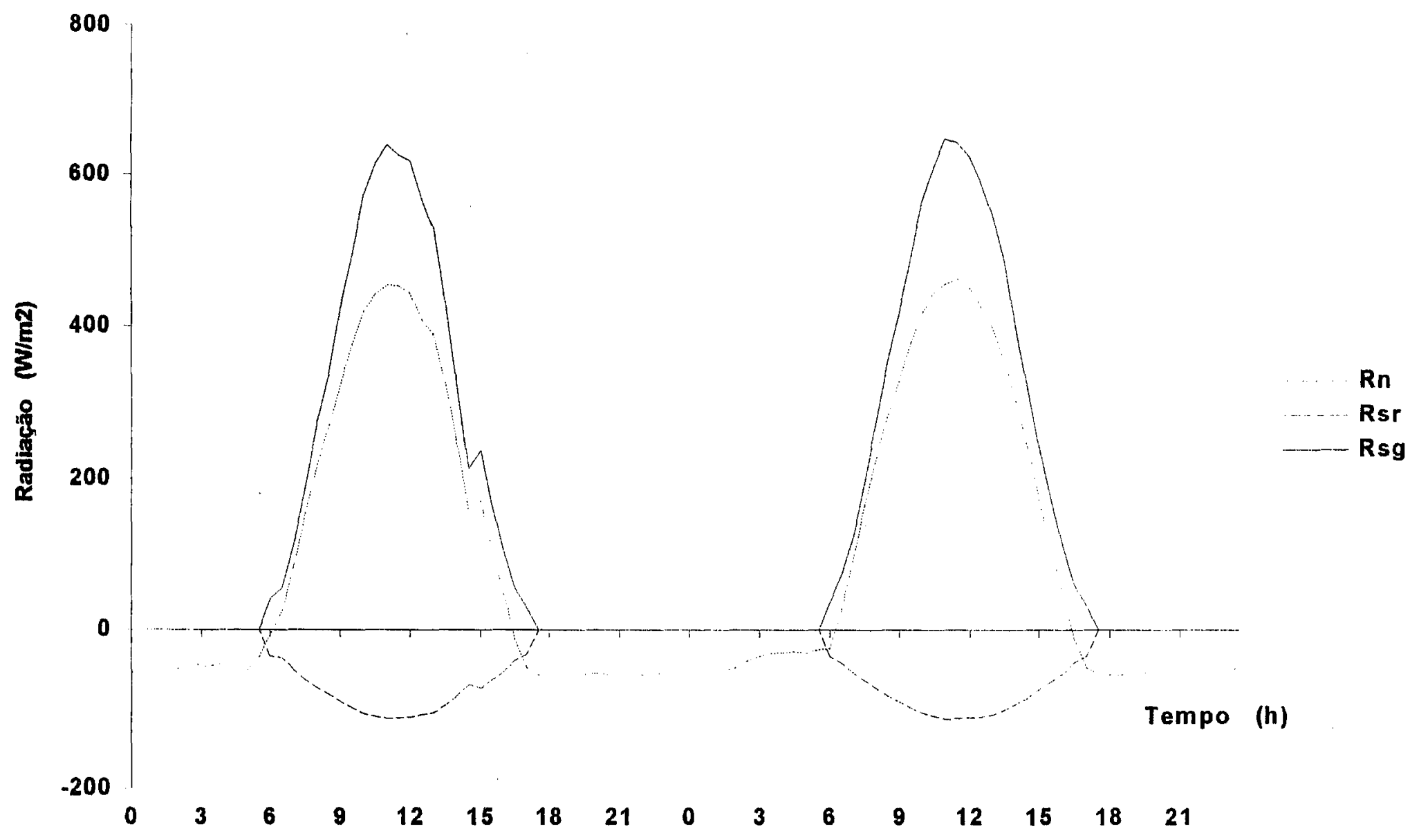

Figura 2 - Valores instantâneos medidos da radiação global incidente (Rsg), radiação de ondas curtas refletida (Rsr) e radiação líquida (Rn), nos dias 03/09/1994 e 04/09/1994, em Santo Antônio do Leverger. 


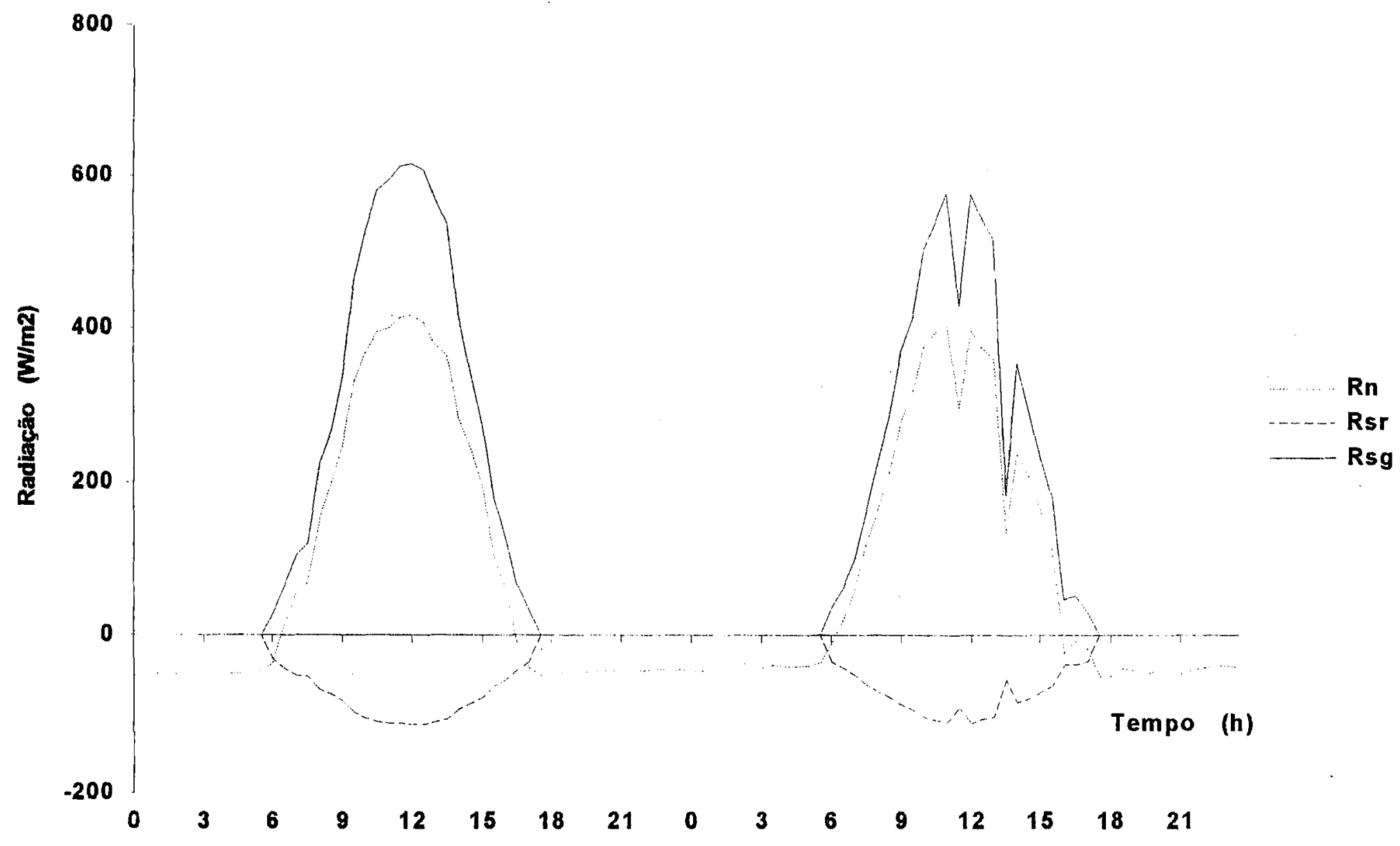

Figura 3 - Valores instantâneos medidos da radiação global incidente (Rsg), radiação de ondas curtas refletida (Rsr) e radiação líquida (Rn), nos dias 10/09/1994 e 11/09/1994, em Santo Antônio do Leverger. 


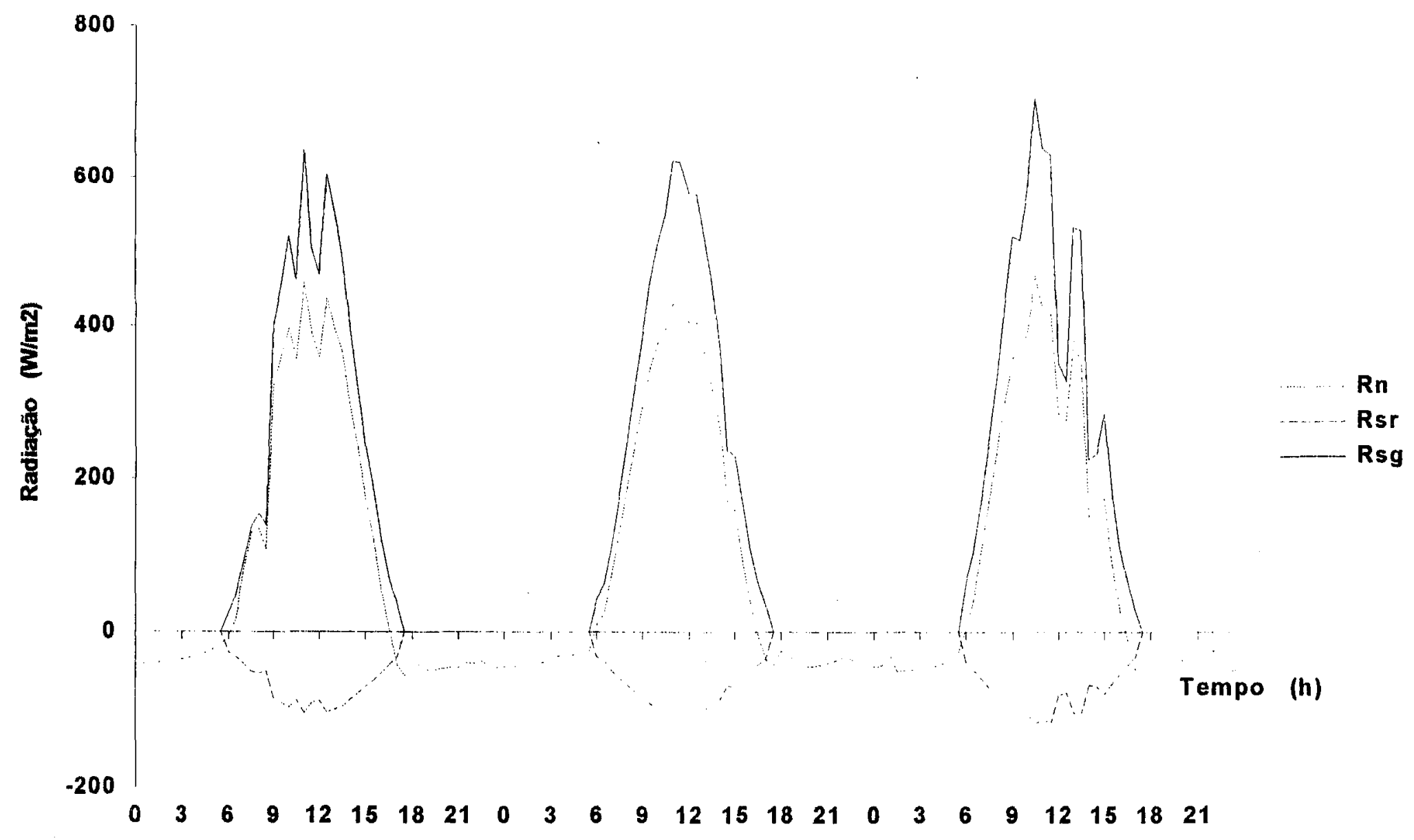

Figura 4 - Valores instantâneos medidos da radiação global incidente (Rsg), radiação de ondas curta refletida (Rsr) e radiação líquida (Rn), nos dias 17/09/1994, 18/09/1994 e 22/09/1994, em Santo Antônio do Leverger. 


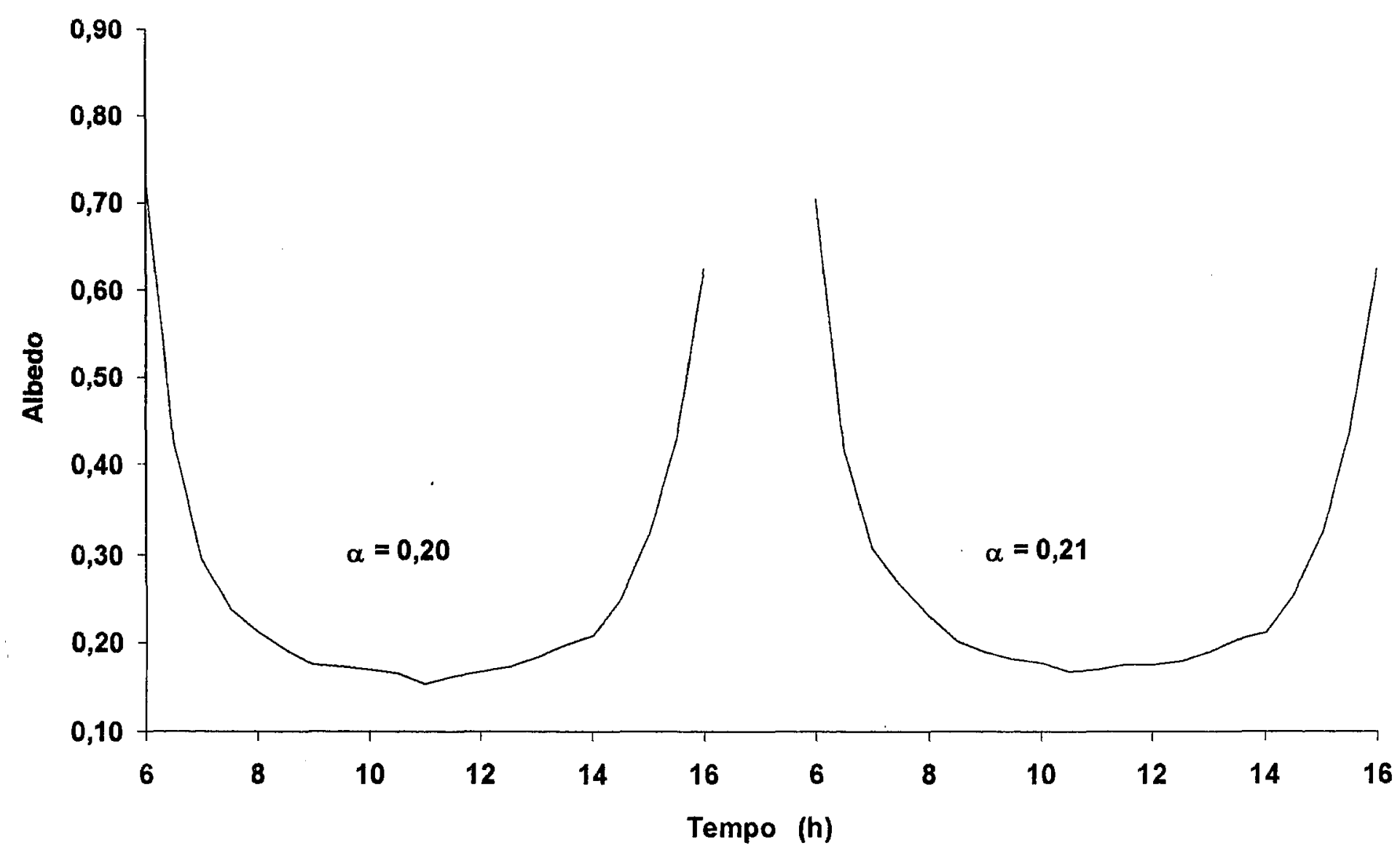

Figura 5 - Albedo da grama ao longo dos dias 11/07/1994 e 12/07/1994, em Santo Antônio do Leverger. 


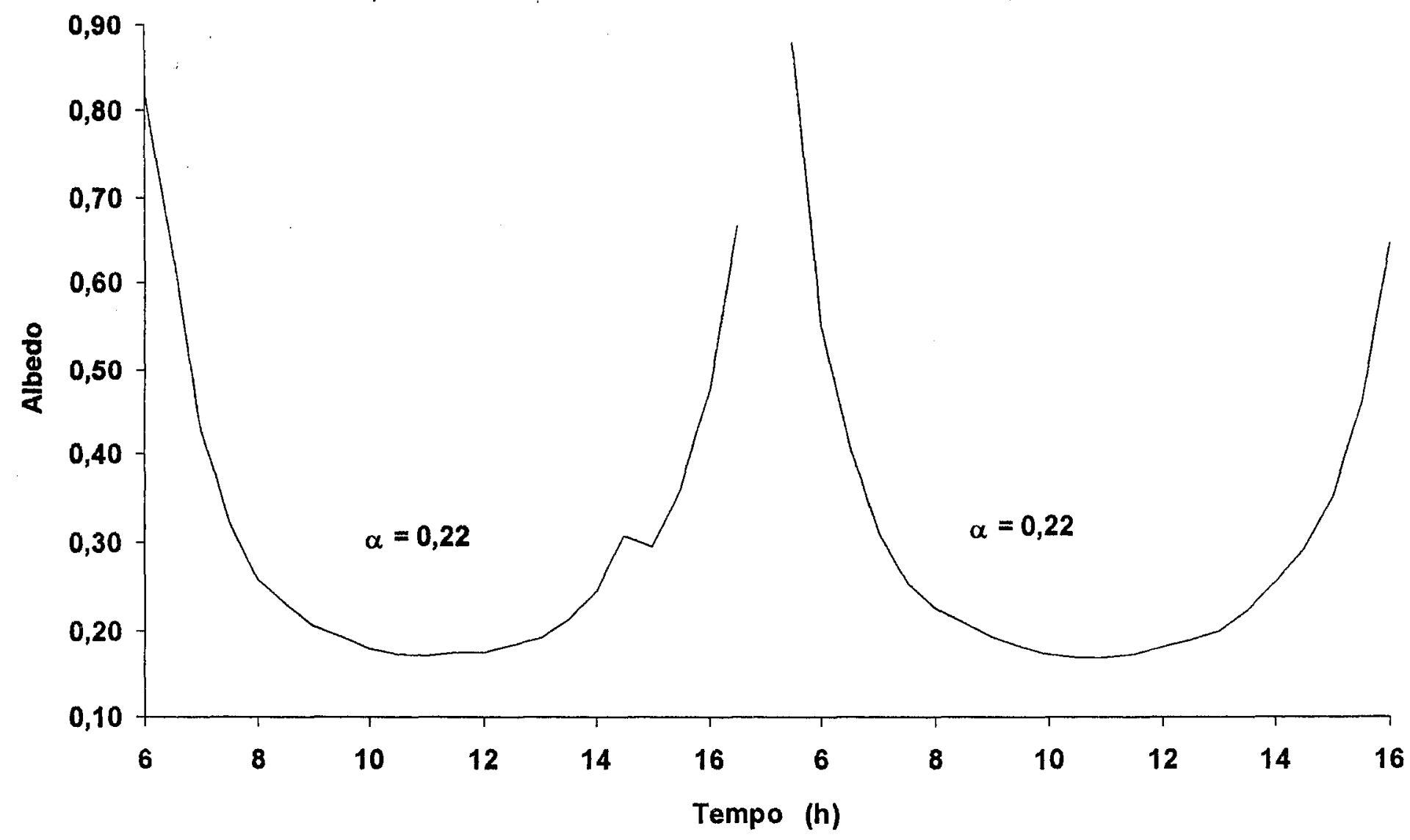

Figura 6 - Albedo da grama ao longo dos dias 03/09/1994 e 04/09/1994, em Santo Antônio do Leverger. 


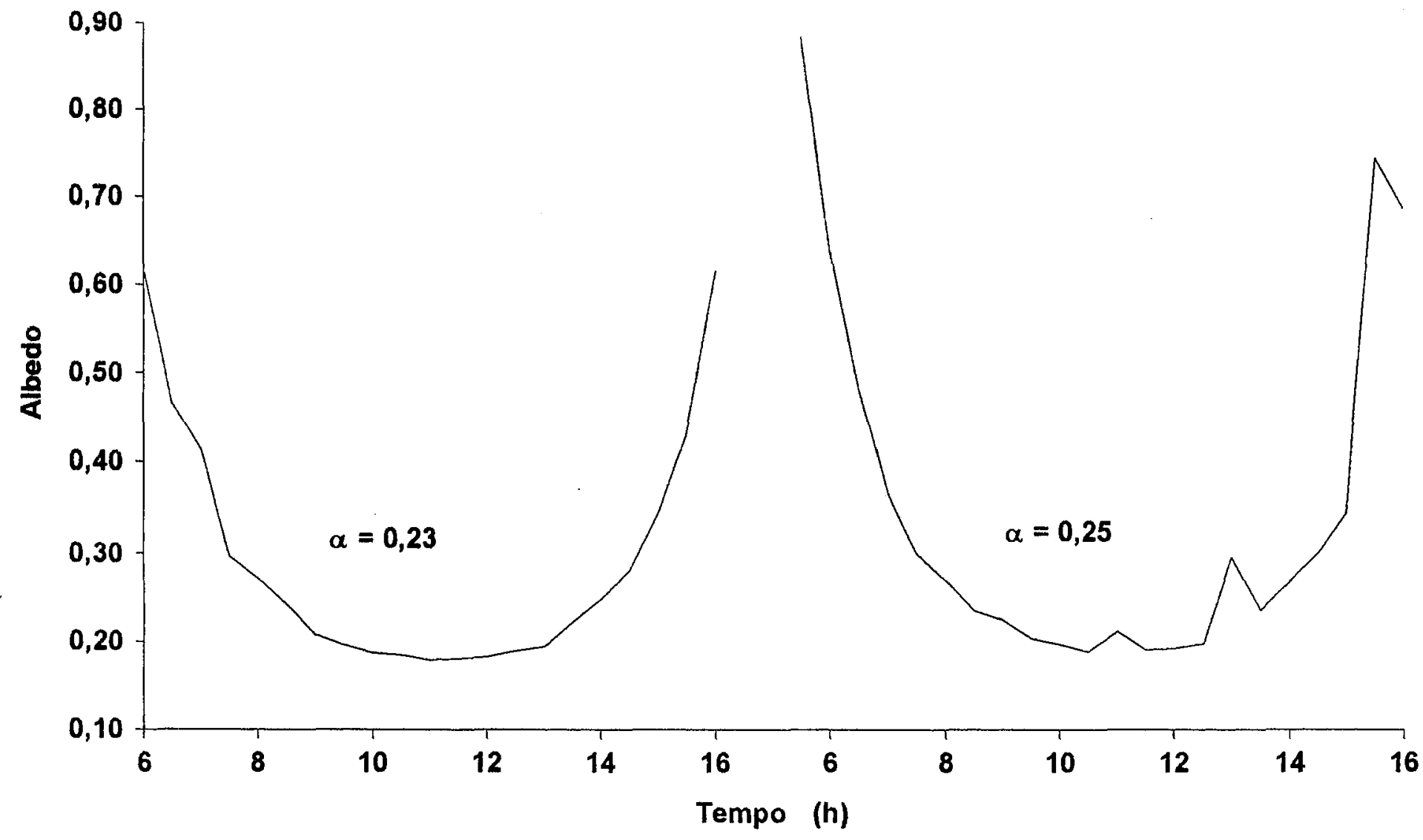

Figura 7 - Albedo da grama ao longo dos dias 10/09/1994 e 11/09/1994, em Santo Antônio do Leverger. 


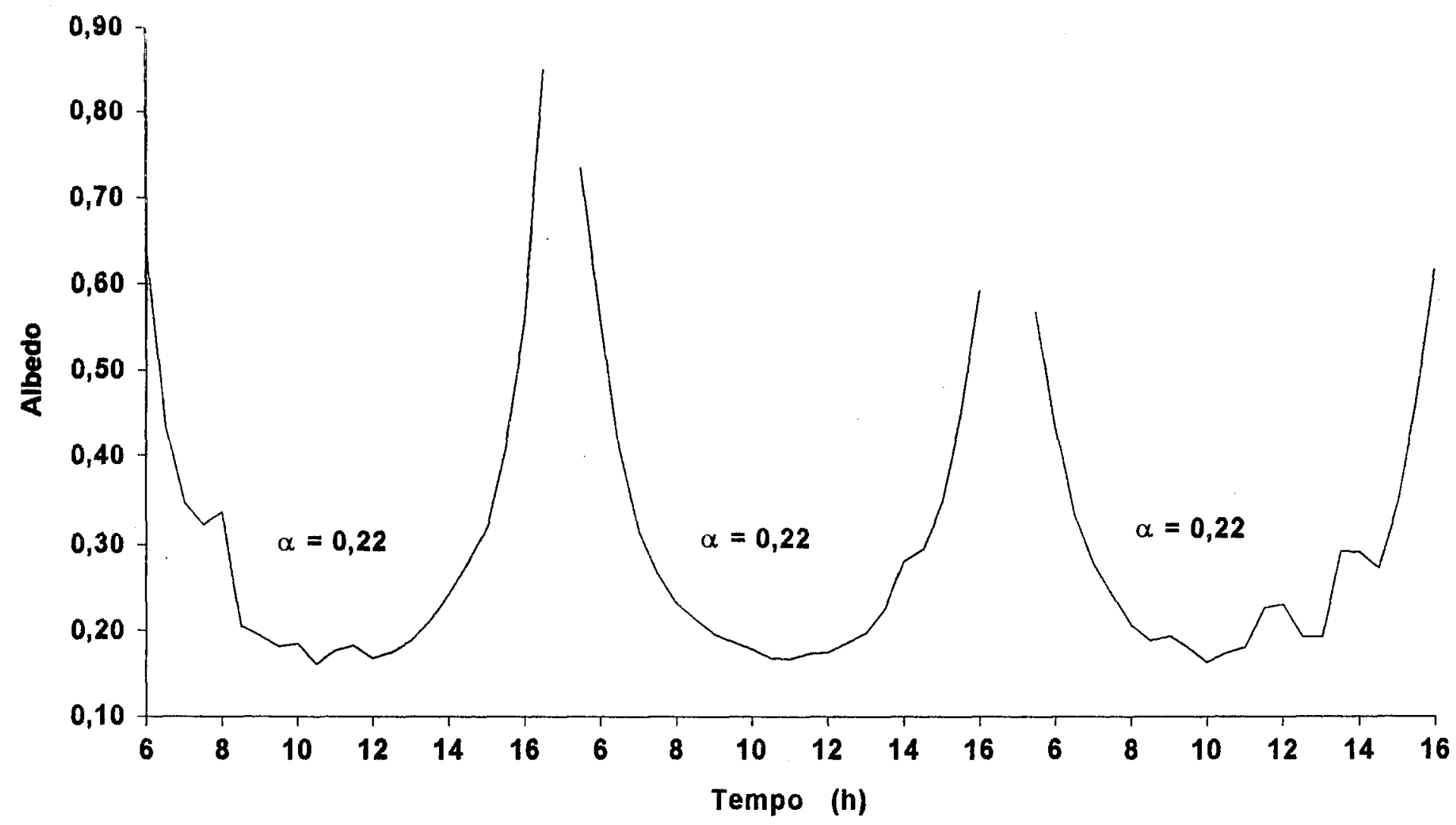

Figura 8 - Albedo da grama ao longo dos dias 17/09/1994, 18/09/1994 e 22/09/1994, em Santo Antônio do Leverger. 


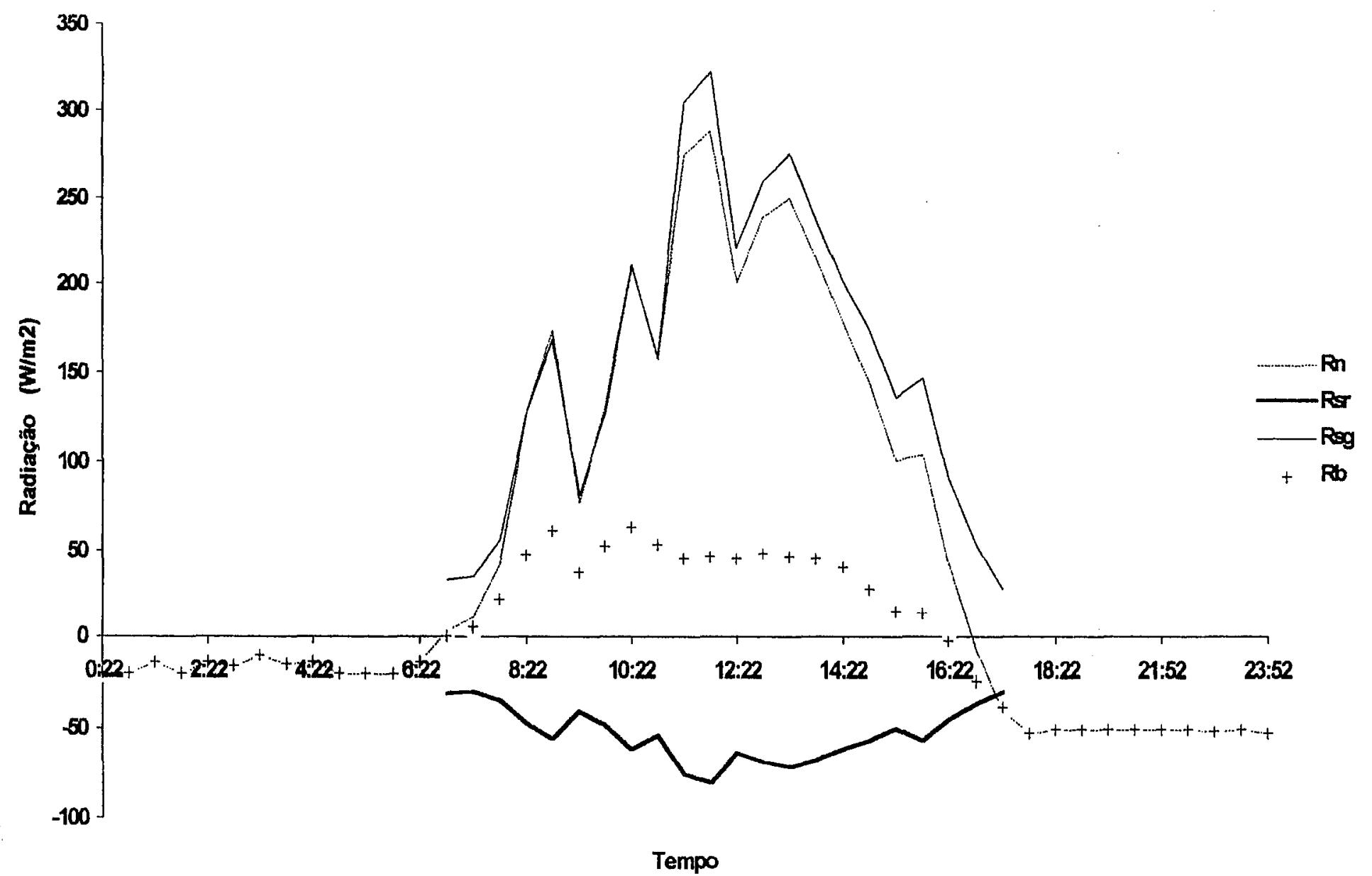

Figura 9 - Valores instantâneos medidos da radiação global incidente (Rsg), radiação de ondas curtas refletida (Rsr), radiação líquida $(R n)$ e balanço de radiação de ondas longas $(R b)$, no dia 02/09/1994, em Santo Antônio do Leverger. 
Tabela 1 - Valores médios diários de temperatura, pressão de vapor, balanço de ondas longas, teor de $\mathrm{CO}_{2}$ e emissividade.

\begin{tabular}{llllllllll}
\hline Data & $11 / 07$ & $12 / 07$ & $03 / 09$ & $04 / 09$ & $10 / 09$ & $11 / 09$ & $17 / 09$ & $18 / 09$ & $22 / 09$ \\
\hline $\mathrm{T}\left({ }^{\circ} \mathrm{C}\right)$ & 18,41 & 20,89 & 19,99 & 22,86 & 25,05 & 28,33 & 27,40 & 28,81 & 30,24 \\
$e(\mathrm{mb})$ & 15,73 & 15,62 & 17,31 & 20,16 & 21,33 & 23,46 & 29,00 & 29,96 & 24,66 \\
$\mathrm{R}_{\mathrm{h}}\left(\mathrm{W} / \mathrm{m}^{2}\right)$ & -45 & -40 & -47 & -44 & -51 & -40 & -38 & -40 & -47 \\
$\mathrm{n} / \mathrm{N}$ & 0,91 & 0,91 & 0,80 & 0,82 & 0,79 & 0,75 & 0,68 & 0,76 & 0,74 \\
$\mathrm{CO}_{3}(\mathrm{ppm})$ & $* *$ & $* *$ & 340 & 345 & 349 & 361 & 358 & 361 & 333 \\
$\varepsilon_{a}$ & 0,89 & 0,91 & 0,89 & 0,90 & 0,89 & 0,91 & 0,92 & 0,92 & 0,90 \\
\hline
\end{tabular}

** Valores não medidos.

Tabela 2 - Emissividade média diária estimada por equações empíricas.

\begin{tabular}{ccccc} 
& BRUNT & SWINBANK & IDSO \& JACKSON & BRUTSAERT \\
\hline Média & 0,8247 & 0,8183 & 0,8399 & 0,8533 \\
Valor de $t$ & $8,66^{* *}$ & $15,62^{* *}$ & $10,23^{* *}$ & $7,62^{* \star}$ \\
\hline
\end{tabular}

** Valor significativo ao nivel de $1 \%$ de probabilidade. 


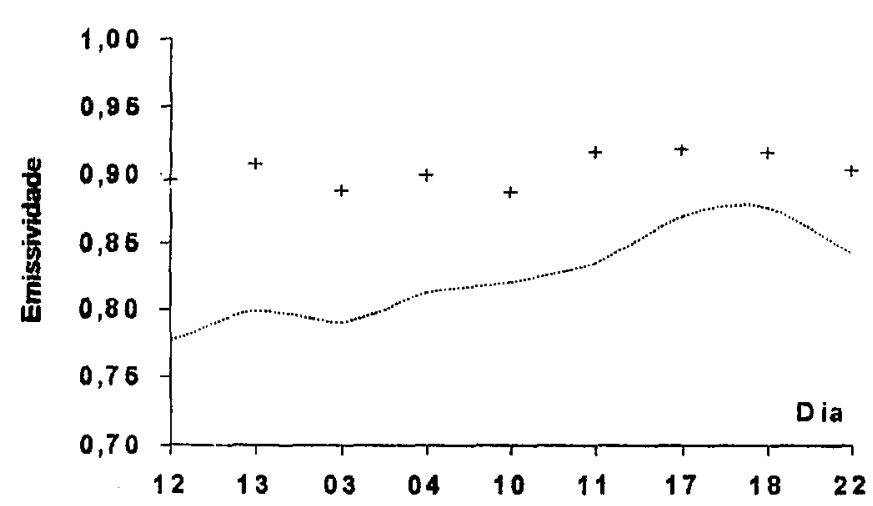

$+\varepsilon_{a}-\cdots \varepsilon_{a}($ Brunt $)$

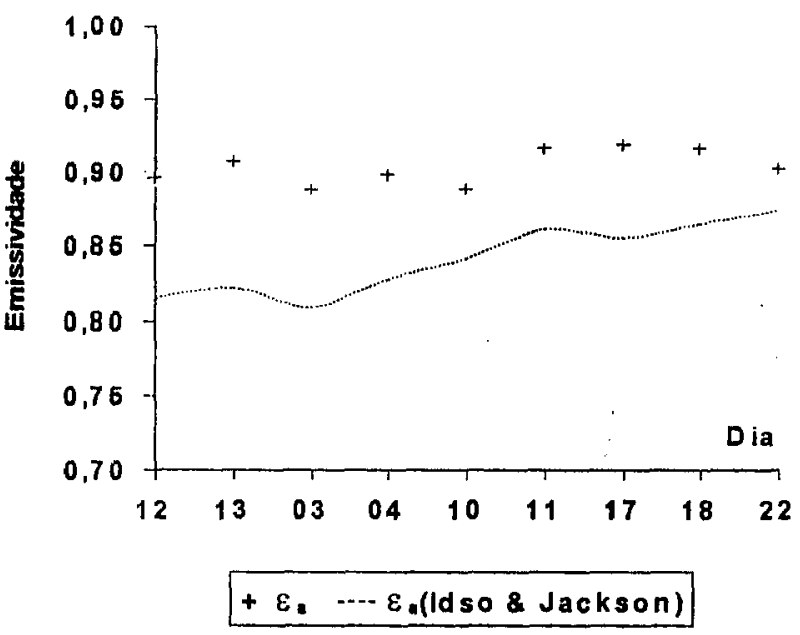

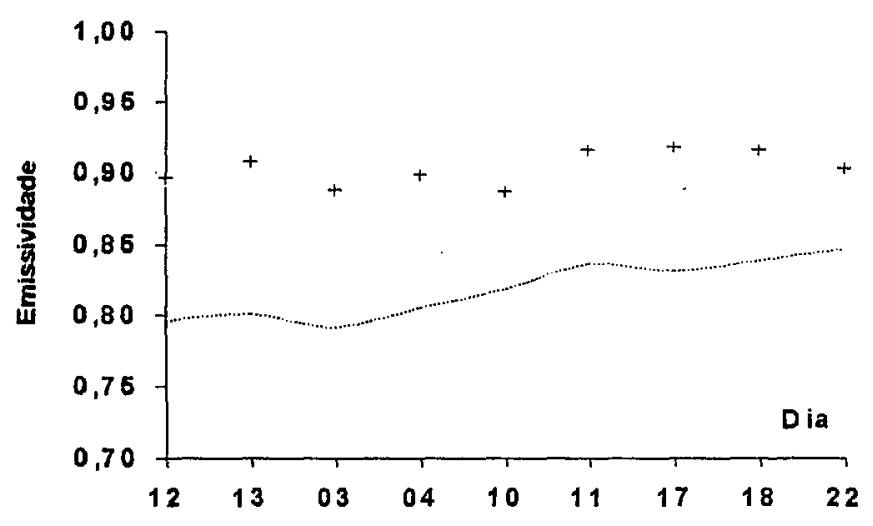

$+\varepsilon_{\mathrm{a}}-\cdots \varepsilon_{\mathrm{a}}(\mathrm{Swinbank})$

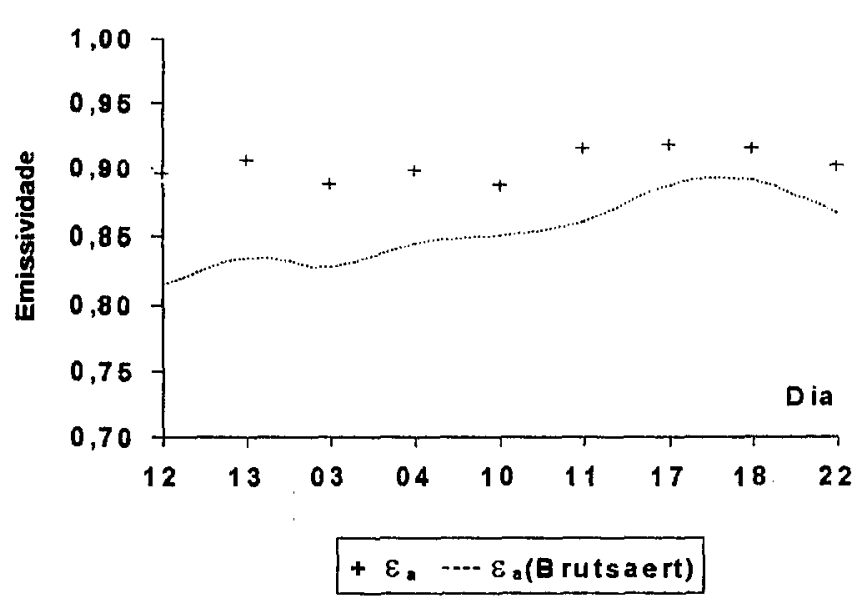

Figura 10 - Emissividades diárias estimadas pelo método do balanço de radiação a partir dos dados deste trabalho e pelos modelos propostos por BRUNT (1932), SWINBANK (1963), IDSO \& JACKSON(1969) e BRUTSAERT(1975). 
38.

Os resultados da Tabela 3 mostram que os valores de emissividade média diária estimados pelas equações empíricas apresentaram baixa correlação com os valores de emissividade obtidos através do balanço de radiação. As diferenças entre os coeficientes de determinação entre a emissividade estimada pelo balanço de radiação e as estimadas por equações empíricas as quais tem variáveis dependentes da pressão de vapor e os da temperatura indicam a existência de uma melhor correlação entre o teor de vapor d'água atmosférico e a pressão de vapor do que a temperatura medidas ao nivel de abrigo. Os baixos valores dos coeficientes de determinação foram relacionados com a da ocorrência de névoa seca e fumaça.

Tabela 3 - Coeficientes de determinação entre a emissividade média diária estimada por equações empíricas e a obtida através do balanço de radiação

\begin{tabular}{cccc}
\hline BRUNT & SWINBANK & IDSO \& JACKSON & BRUTSAERT \\
$0,524^{* *}$ & $0,394^{\star *}$ & $0,395^{\star \star}$ & $0,515^{\star *}$ \\
\hline
\end{tabular}

** Valor significativo ao nível de $1 \%$ de probabilidade.

A fim de verificar a possibilidade de se efetuar um ajuste local nos coeficientes das equações empíricas, procedeu-se a análise da correlação entre a emissividade obtida com o balanço de radiação e as variáveis utilizadas nas equações empíricas. Como a regressão estabelecida inicialmente por SWINBANK (1963) foi entre o logaritmo da radiação de ondas longas incidente e o logaritmo da temperatura de bulbo seco, o ajuste local dos coeficientes foi obtido através da análise da regressão linear entre $\log \left(\varepsilon_{a}\right)$ e $\log (T)$, com temperatura em $K$. No 
modelo de IDSO \& JACKSON (1969) as variáveis foram $\operatorname{Ln}\left(1-\varepsilon_{a}\right)$ e $T^{2}$, com temperatura em ${ }^{\circ} \mathrm{C}$. Nos modelos de BRUNT (1932) e de BRUTSAERT(1975) a variável dependente foi $\varepsilon_{a} e$ as variáveis independentes foram $\mathrm{e}^{0,5} \mathrm{e}(\mathrm{e} / \mathrm{T})^{1 / 7}$.

As análises de correlação linear entre a emissividade e as respectivas variáveis de cada um daqueles quatro modelos empíricos revelaram diferentes graus de ajuste (Figura 11).

As melhores estimativas foram obtidas com o ajuste local dos coeficientes das equaçōes de BRUNT (1932) e BRUTSAERT (1975). As equações de SWINBANK (1963) e IDSO \& JACKSON (1969) tiveram pior desempenho e foram equivalentes entre si quando analisadas em relação aos coeficientes de determinação.

Assim sendo o vapor d'água atmosférico, que é o maior responsável pela reemissão da radiação de ondas longas, proporcionou - melhor ajuste para as equaçōes de BRUNT (1932) e BRUTSAERT (1975). As equações de SWINBANK (1963) e IDSO \& JACKSON (1969) em que a emissividade é uma função apenas da temperatura proporcionaram menor correlação entre a emissividade e a temperatura no interior do abrigo.

Embora as análises estatísticas tenham demonstrado que nenhuma das equaçōes ou modelos empíricos foi capaz de reproduzir rigorosamente o comportamento da emissividade, para efeitos práticos de estimativa da disponibilidade de energia radiante diária, qualquer uma das equaçōes proporcionaria erros inferiores a $10 \%$ da emissão efetiva terrestre em dias limpos, ou o equivalente a $3 \%$ do balanço de energia sem advecçāo, produzindo portanto resultados satisfatórios. 

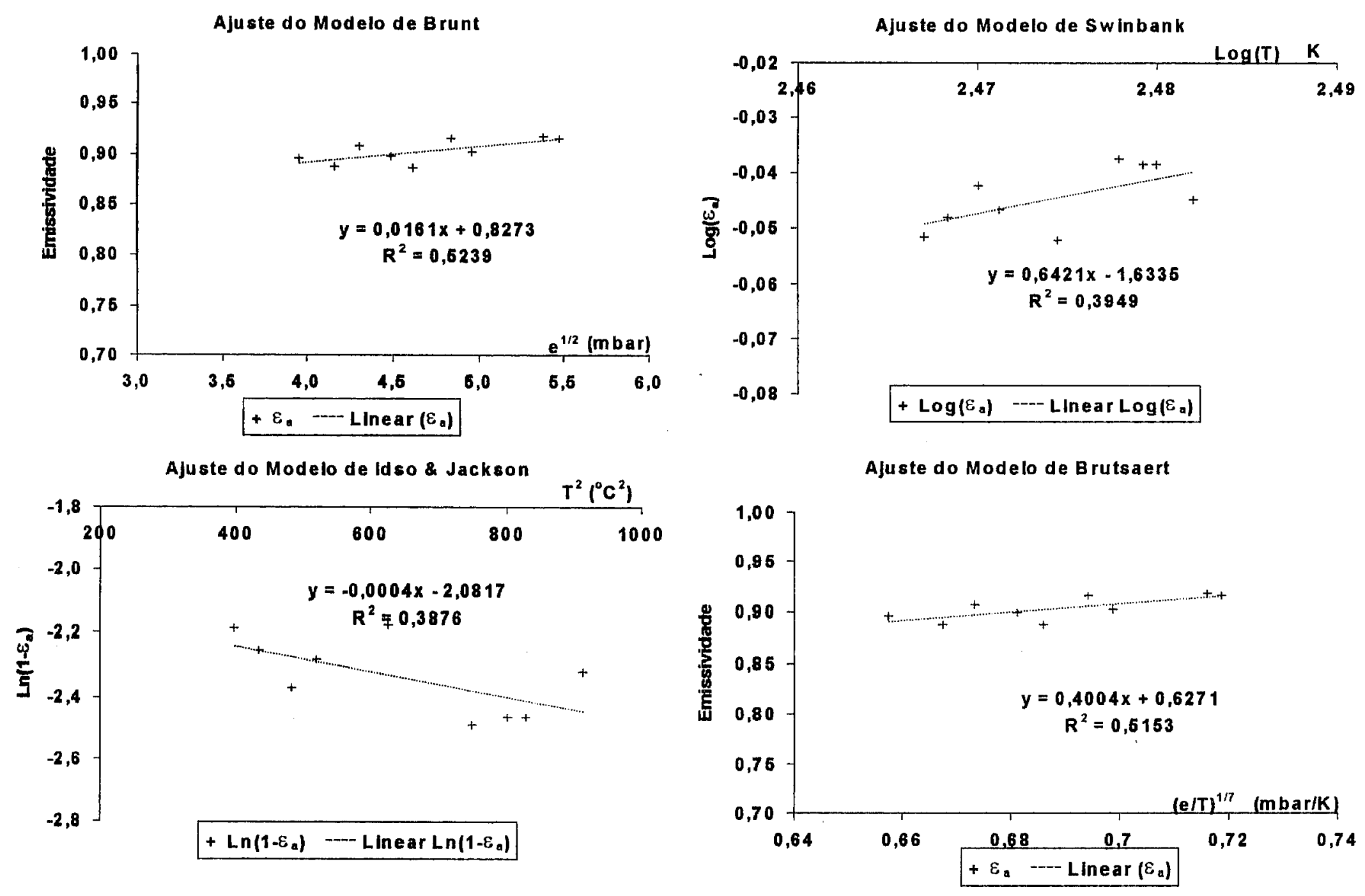

Figura 11 - Ajuste dos modelos de BRUNT (1932), SWINBANK (1963), IDSO \& JACKSON(1969) e BRUTSAERT(1975), dados diários. 
41.

\subsection{Emissividade Diurna}

Como a emissividade média diária estimada pelo balanço de radiação foi maior que a estimativa proporcionada pelas equações empíricas, analisou-se o efeito do vapor d'água e do $\mathrm{CO}_{2}$ associados de modo linear, porém a análise se restringiu aos periodos diurnos do mês de setembro, quando se dispunha de registros de medidas do teor de gás carbônico atmosférico.

Para efeito de comparação com essa abordagem do efeito dos dois gases, a emissividade diurna foi também estimada pelas equaçōes de BRUNT (1932), SWINBANK (1963), IDSO \& JACKSON (1969) e BRUTSAERT(1975), cujos resultados se encontram na Tabela 4 e nas Figuras 12 e 13, de modo análogo ao procedimento efetuado para a análise da emissividade média diária.

O valor médio da emissividade média diurna foi praticamente igual ao valor médio diário. As médias das diferentes estimativas apresentaram diferenças significativas em relação ao valor médio de 0,8993, obtido por meio do balanço de radiaçāo (Tabela 4).

Tabela 4 - Emissividade média diurna estimada por equações empíricas.

\begin{tabular}{lcccc} 
& BRUNT & SWINBANK & IDSO \& JACKSON & BRUTSAERT \\
\hline Média & 0,8347 & 0,8426 & 0,8676 & 0,8592 \\
Valor de t & $5,73^{\star *}$ & $7,19^{* *}$ & $3,82^{\star *}$ & $4,80^{* *}$ \\
\hline
\end{tabular}

** Valor significativo ao nível de $1 \%$ de probabilidade 

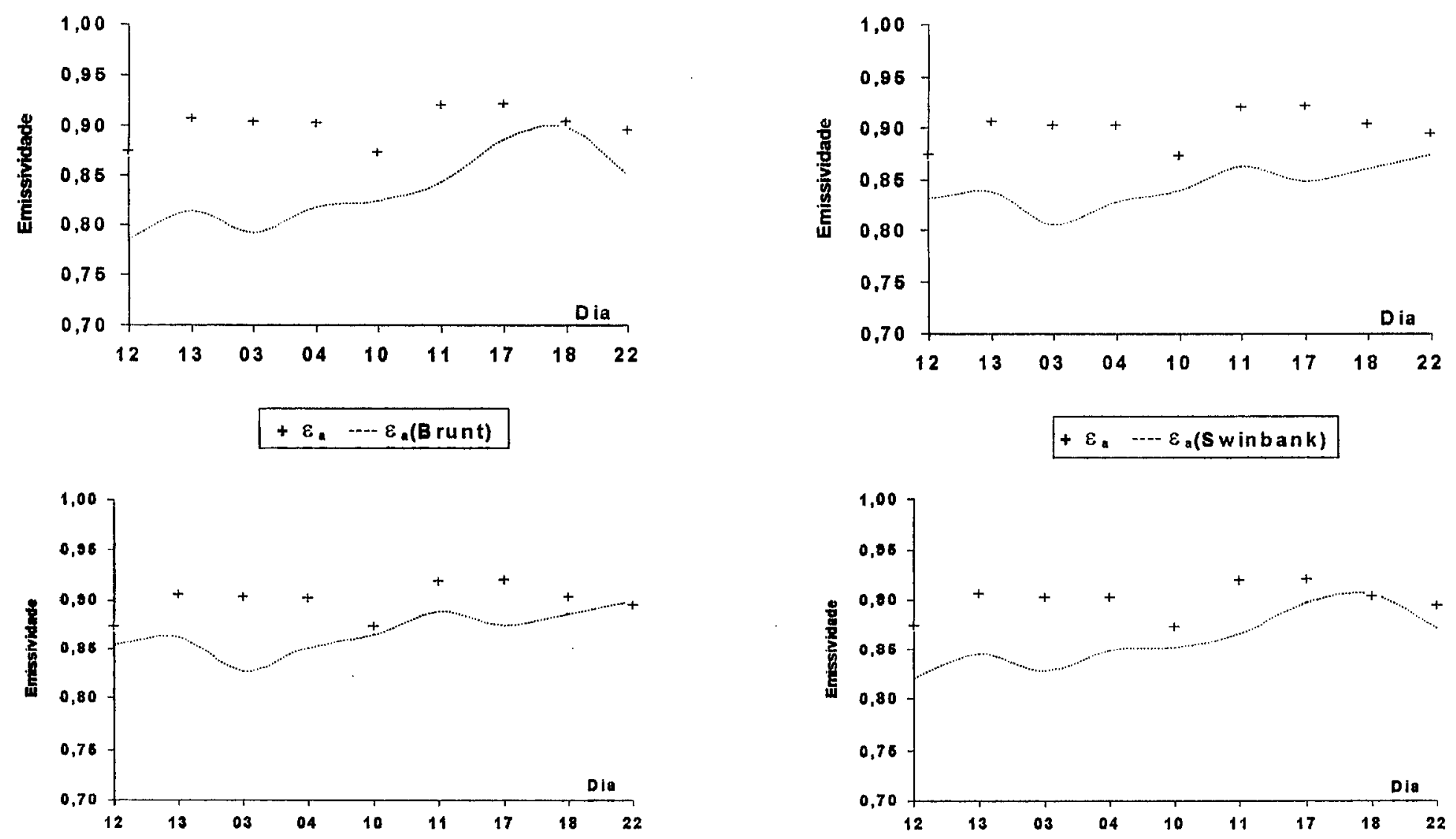

$+\varepsilon_{a} \quad \cdots-\varepsilon_{a}($ lds so \& Jackson $)$

$+\varepsilon_{a} \quad \cdots \varepsilon_{a}($ B rutsaert $)$

Figura 12 - Emissividades diurnas estimadas pelos métodos do balanço de radiação a partir dos dados deste trabalho e pelos modelos propostos por BRUNT (1932), SWINBANK (1963), IDSO \& JACKSON(1969) e BRUTSAERT(1975). 
43.

Tabela 5 - Coeficientes de determinação entre a emissividade média diurna estimada por equações píricas e a obtida através do balanço de radiação

\begin{tabular}{cccc}
\hline BRUNT & SWINBANK & IDSO \& JACKSON & BRUTSAERT \\
$0,245^{\star \star}$ & $0,047^{\star \star}$ & $0,046^{\star \star}$ & $0,257^{\star \star}$ \\
\hline
\end{tabular}

** Valor significativo ao nível de $1 \%$ de probabilidade.

Os resultados da Tabela 5 mostram que os valores de emissividade diurna estimados pelas equações empíricas apresentaram baixa correlação com os valores de emissividade obtidos através do balanço de radiação.

A forte redução nos coeficientes de determinação do período diurno, comparado com as média diárias devem ter ocorrido em conseguência da dificuldade de medida da radiação líquida nos períodos de incidência da radiação de ondas curtas, conforme já mencionado.

Preliminarmente, a influência do $\mathrm{CO}_{2}$ na emissividade do céu foi analisada em dados médios de nove dias, usando-se de regressão múltipla para verificar a correlação existente entre a emissividade do céu claro estimada pelo balanço de radiaçāo e os teores de água e gás carbônico. O coeficiente de determinação obtido foi de 0,70 (MENDONÇA et alii. ,1995a). Entretanto, é necessário salientar que essa análise preliminar foi realizada antes de se detectar as dificuldades de medida dos componentes do balanço de radiação no início e no final do periodo diurno. 
Ajuste do Modelo de Brunt

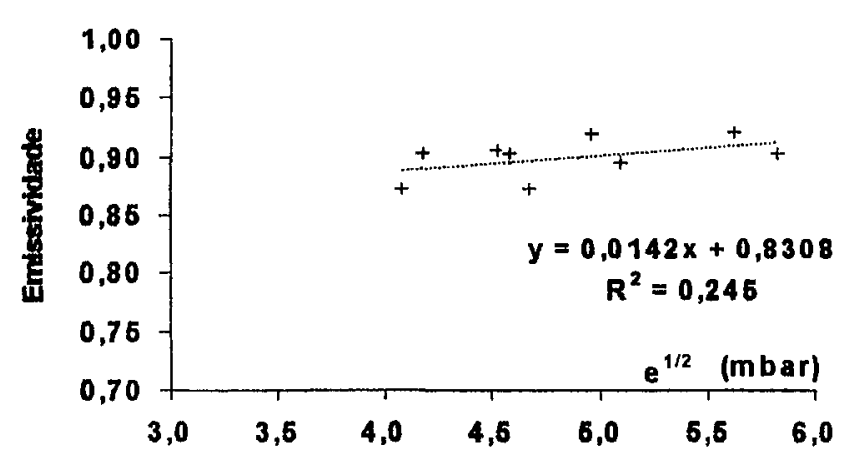

$+\varepsilon_{a} \quad--\operatorname{Linear}\left(\varepsilon_{a}\right)$

Ajuste do Modelo de Idso \& Jackson

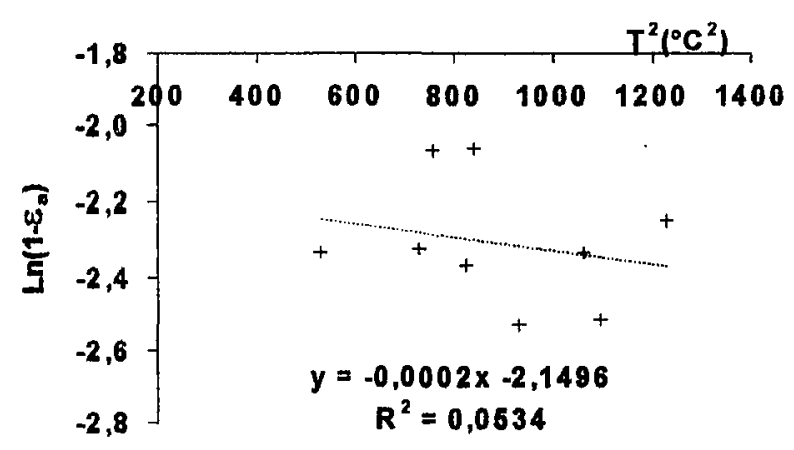

$+\operatorname{Ln}\left(1-\varepsilon_{a}\right)--\operatorname{Lnear} \operatorname{Ln}\left(1-\varepsilon_{a}\right)$
Ajuste do Modelo de $S$ winbank

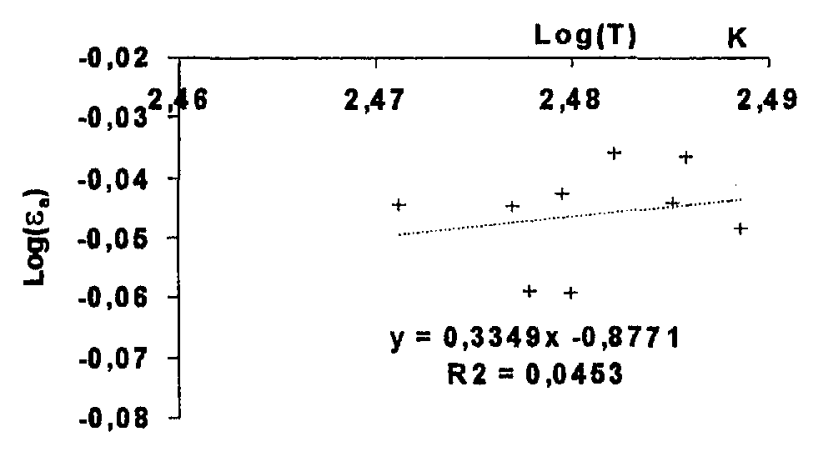

$+\log \left(\varepsilon_{a}\right)-\operatorname{Lnear} \log \left(\varepsilon_{a}\right)$

Ajuste do Modelo de B rutsaert

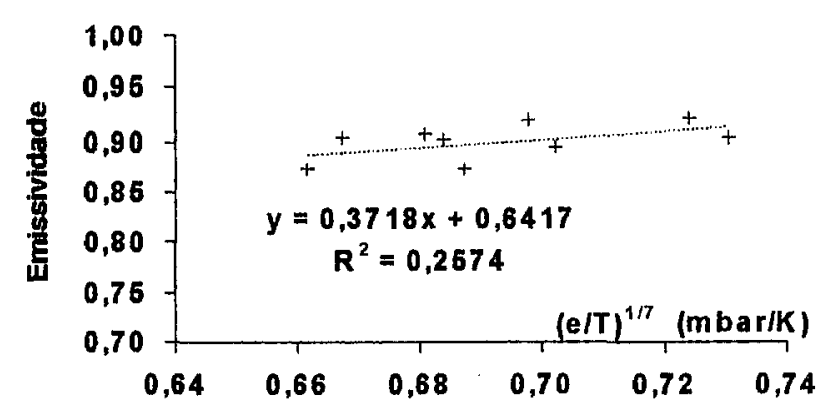

$+\varepsilon_{a} \quad-\cdots \operatorname{Linear}\left(\varepsilon_{a}\right)$

Figura 13 - Ajuste dos modelos de BRUNT (1932), SWINBANK (1963), IDSO \& JACKSON(1969) e BRUTSAERT(1975), dados diurnos. 
As análises posteriores do efeito do vapor d'água e gás carbônico revelaram os resultados abaixo, em que o coeficiente de determinação foi praticamente igual ao obtido com o modelo de BRUNT (1932). Não obstante, nenhum dos demais métodos empíricos estudados proporcionou estimativas satisfatórias da emissividade no periodo diurno.

$$
\varepsilon_{a}=0,678+3,3410^{-3} e^{0,5}+5,9310^{-4} \mathrm{CO}_{2}\langle p p m\rangle
$$

onde $n=7$ e $R^{2}=0,233$, sendo significativa ao nível de $1 \%$ de probabilidade de acordo com o teste $F$ de Snedecor.

As estimativas da emissividade do céu levando em consideração o teor de $\mathrm{CO}_{2}$ atmosférico não provocaram uma mudança significativamente importante, provavelmente porque a influência do gás carbônico é modesta. O valor máximo da emissividade do $\mathrm{CO}_{2}$, numa atmosfera seca, é de cerca de 0,18 a 0,20 , ocorrendo emissão na faixa do espectro entre 13 e $17 \mu \mathrm{m}$. Entretanto, o acréscimo máximo provocado pelo $\mathrm{CO}_{2}$ na emissividade da atmosfera que contêm vapor de água é de aproximadamente 0,08 , obtidos para uma coluna d'água de aproximadamente $1 \mathrm{~g} / \mathrm{cm}^{2}$, que equivale a um teor de umidade relativamente baixo (BLISS JR, 1961). Outro motivo que poderia concorrer para não se dar relevância à influência do $\mathrm{CO}_{2}$ é a sua variação pequena em relação a variação do teor de água da atmosfera. Conseqüentemente, de algum modo sua influência pode estar incluída nas constantes das equaçōes de regressão normalmente utilizadas. 
De acordo com os valores apresentados nas Tabelas 4 e 6 foi possivel verificar que para os valores médios diurnos estimado pelos métodos em estudo, os coeficientes de determinação foram menores do que para os médios diários, devendo existir diferença diuturna nos perfis de temperatura-umidade conforme também encontrado por GULF \& GASH (1993).

\subsection{Emissividade Noturna}

Como os dados analisados por SWINBANK (1963) foram originalmente medidos no periodo noturno, principalmente no período entre as 20:00 e 21:00 h, foi selecionada uma série de 28 dados instantâneos obtidos nesse período no presente estudo, para verificar o ajuste das constantes empíricas do modelo em condiçōes mais semelhantes às originais, pois VISWANADHAM \& MASCARENHAS JR. (1978) referiram-se a uma possivel influência das condições de estabilidade atmosférica na emissividade, e, neste horário e local, de acordo com MENDONÇA (1995b), as condições atmosféricas propiciaram a ocorrência de fraca a forte inversão térmica.

A emissividade da atmosfera em dias sem nuvens foi determinada através do balanço de radiaçāo, sem levar em consideração - fator de correção pela presença de nuvens, pois as noites consideradas eram principalmente claras (condição predominante nesta época do ano na região).

No periodo diurno, havia se constatado, por observação visual e pela análise dos diagramas de registro do heliógrafo, que o céu 
esteve apenas parcial e temporariamente coberto por nuvens. Desse modo, as medidas instantâneas de meia em meia hora praticamente não foram afetadas pela presença de nuvens. De outro lado, a bibliografia consultada sugere que as medidas não sejam realizadas em períodos de ocorrência de nuvens, e no caso noturno a avaliação de ocorrência ou não de nuvens seja realizada por detectores infravermelho de nuvens, conforme BERDAHI \& FROMBERG (1982), ou por simples visualização de estrelas de acordo com GULF \& GASH (1993), SENTENO, V. (1982). No caso diurno o critério de correção utilizado por SENTENO, V. (1982) leva em consideração a porção do céu coberto e o tipo de nuvens. A validade desse tipo de correção tem se restringido a dados diários ou até mesmo horários (SUGITA e BRUTSAERT, 1993).

É necessário observar que à noite, no horário estudado, deve ter sido praticamente desprezivel a influência direta da radiação/temperatura nos instrumentos de medida de radiação e temperatura, e também quase nula a ocorrência de orvalho, sendo este fator importante, pois o net-radiômetro utilizado não era ventilado e não deve ter ocorrido deposição de orvalho no termômetro de bulbo seco. 
48.

Tabela 6 - Radiação efetiva de ondas longas $\left(R_{b}\right)$, Temperatura $(T)$, pressão de vapor atual (e), noturnos instantâneos, entre 20 e 21 horas, medidos em Santo Antônio do Leverger, em 1994 (julho, agosto e setembro)

\begin{tabular}{|c|c|c|c|c|}
\hline Data & Horário & $\mathrm{Rb}(\mathrm{W} / \mathrm{m} 2)$ & $\mathrm{T}\left({ }^{\circ} \mathrm{C}\right)$ & e (mbar) \\
\hline $13 / 07$ & $20: 07$ & -48 & 16,21 & 17,47 \\
\hline $13 / 07$ & $20: 37$ & -47 & 17,03 & 17,38 \\
\hline $30 / 08$ & $20: 03$ & -45 & 24,29 & 24,53 \\
\hline $30 / 08$ & $20: 33$ & -45 & 26,14 & 23,29 \\
\hline $30 / 08$ & $21: 03$ & -43 & 23,95 & 24,24 \\
\hline $02 / 09$ & $19: 52$ & -52 & 18,52 & 16,16 \\
\hline $02 / 09$ & $20: 22$ & -51 & 18,08 & 16,66 \\
\hline $03 / 09$ & $20: 22$ & -52 & 19,05 & 20,32 \\
\hline $03 / 09$ & $20: 52$ & -54 & 19,12 & 19,52 \\
\hline $04 / 09$ & $19: 52$ & -49 & 21,29 & 22,26 \\
\hline $04 / 09$ & $20: 22$ & -49 & 20,48 & 21,68 \\
\hline $09 / 09$ & $20: 11$ & -57 & 22,20 & 19,03 \\
\hline $09 / 09$ & $20: 41$ & -54 & 21,54 & 18,88 \\
\hline $09 / 09$ & $21: 11$ & -52 & 20,04 & 19,76 \\
\hline $10 / 09$ & $20: 11$ & -43 & 24,27 & 24,03 \\
\hline $10 / 09$ & $20: 41$ & -42 & 23,48 & 23,48 \\
\hline $11 / 09$ & $20: 11$ & -44 & 26,39 & 22,52 \\
\hline $11 / 09$ & $20: 41$ & -45 & 26,43 & 21,99 \\
\hline $16 / 09$ & $20: 13$ & -29 & 25,54 & 28,14 \\
\hline $16 / 09$ & $20: 43$ & -29 & 25,01 & 27,88 \\
\hline $17 / 09$ & $20: 13$ & -45 & 25,05 & 25,40 \\
\hline $17 / 09$ & $20: 43$ & -43 & 24,37 & 26,23 \\
\hline $18 / 09$ & $20: 13$ & -42 & 27,86 & 25,14 \\
\hline $18 / 09$ & $20: 43$ & -40 & 26,00 & 25,58 \\
\hline $21 / 09$ & $19: 55$ & -22 & 25,56 & 24,69 \\
\hline $21 / 09$ & $20: 25$ & -26 & 27,81 & 26,93 \\
\hline $22 / 09$ & $19: 55$ & -35 & 27,40 & 25,27 \\
\hline $22 / 09$ & $20: 25$ & -34 & 27,35 & 24,66 \\
\hline
\end{tabular}


49.

Os valores utilizados para a análise estatística da emissividade instantânea noturna, entre 20 e 21 horas estão na Tabela 6.

O valor médio da emissividade atmosférica noturna no período entre as 20 e 21 horas foi de 0,8996 .

A utilização das equações originais de BRUNT (1932), SWINBANK (1963), IDSO \& JACKSON (1969) e BRUTSAERT (1975) subestimou os valores noturnos da radiação de ondas longas incidente (Tabela 7).

Tabela 7 - Emissividade média noturna estimada por equações empíricas.

\begin{tabular}{ccccc}
\hline & BRUNT & SWINBANK & IDSO \& JACKSON & BRUTSAERT \\
\hline Média & 0,8282 & 0,8082 & 0,8278 & 0,8573 \\
Valor de t & $27,64^{\star *}$ & $32,82^{\star \star}$ & $25,57^{\star \star}$ & $16,51^{\star *}$ \\
\hline
\end{tabular}

** Valor significativo ao nível de $1 \%$ de probabilidade.

Os resultados da Tabela 8 mostram que os valores de emissividade noturna estimados pelas equações empíricas apresentaram baixa correlação com os valores de emissividade obtidos através do balanço de radiação.

Tabela 8 - Coeficientes de determinação entre a emissividade média noturna estimada por equaçōes empíricas e a obtida através do balanço de radiação

\begin{tabular}{ccccc}
\hline BRUNT & SWINBANK & IDSO \& JACKSON & BRUTSAERT \\
$0,699^{* *}$ & $0,614^{* *}$ & $0,619^{* *}$ & $0,688^{* *}$ \\
\hline Valor & significativo & ao nivel de $1 \%$ & de & probabilidade.
\end{tabular}




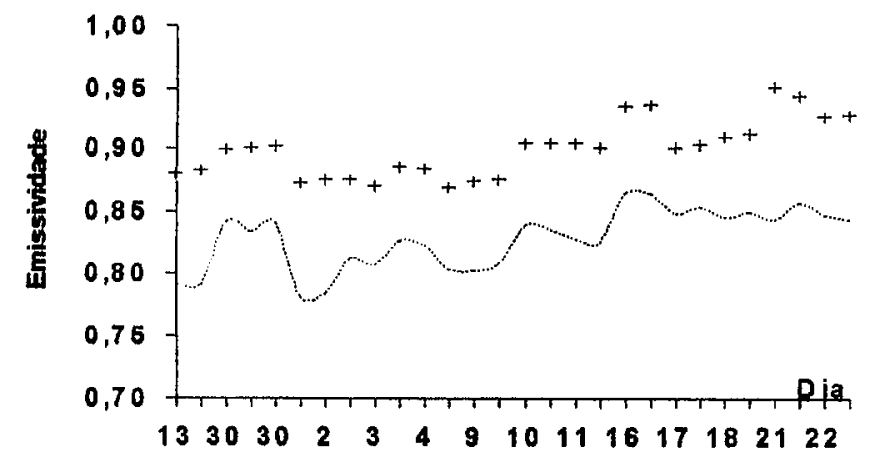

$+\varepsilon_{a} \quad--\varepsilon_{a}($ Brunt $)$

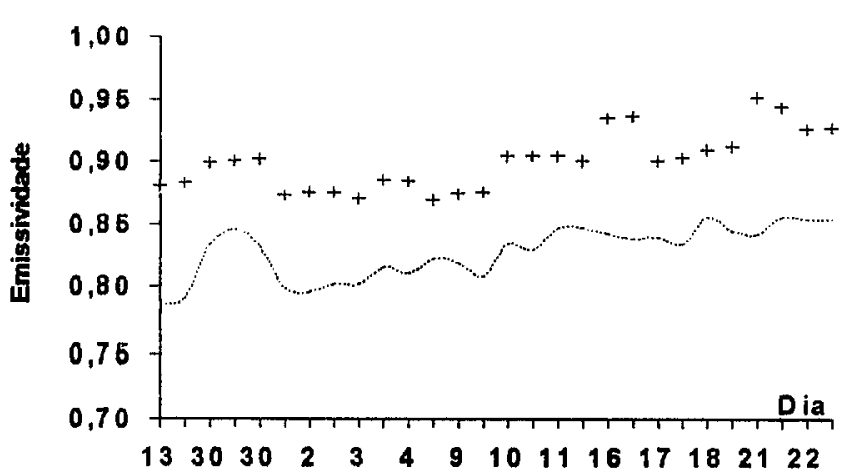

$+\varepsilon_{4}-\cdots \varepsilon_{a}($ ldso \& Jackson $)$

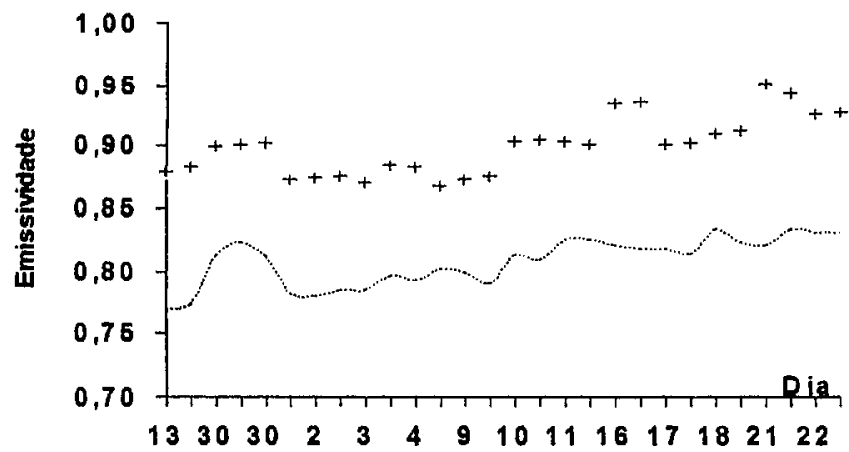

$+\varepsilon_{a} \ldots \varepsilon_{\mathrm{a}}(S$ win bank $)$

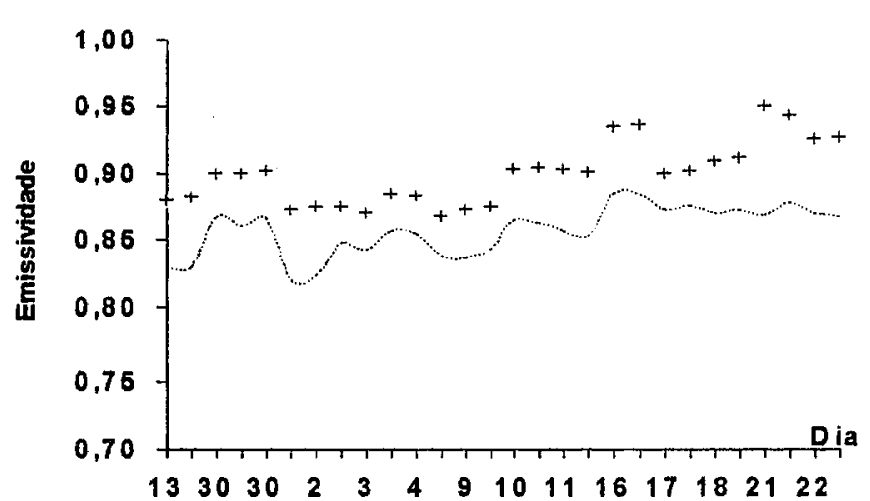

$+\varepsilon_{a}-\cdots \varepsilon_{a}($ Brutsaert)

Figura 14- Emissividades de dados noturnos estimados pelo balanço de radiação a partir dos dados deste trabalho e pelos modelos propostos por BRUNT (1932), SWINBANK (1963), IDSO \& JACKSON(1969) e BRUTSAERT(1975). 
CULF \& GASH (1993) encontraram um coeficiente de determinação de 0,76 entre a emissividade medida e a estimada pela eq. 6 de SWINBANK (1963), tomando por base 176 medidas horárias com céu claro ( quando a razão entre a radiação solar difusa e a total foi menor ou igual a 0,18 e para dados noturnos em que a visibilidade de estrelas indicava pouca cobertura de nuvens), realizadas nas estações seca e úmida entre 15/07/1989 e 30/09/1990, no Níger.

CULF \& GASH (1993) aconselham cuidado no uso das equações empíricas com os coeficientes originais, para locais e estações diferentes daquelas em que foram desenvolvidas, pois determinaram que a tendência da equação 1 de BRUNT (1932) e a equação 12 de BRUTSAERT (1975) é subestimar a radiação de ondas longas incidente, enquanto a equação 7 de SWINBANK (1963) e a equação 11 de IDSO \& JACKSON é de superestimar, provocando erros na estimativa da radiação liquida de $-44 \%, 18 \%, 58 \%$ e $72 \%$, respectivamente.

IDSO \& JACKSON (1969), analisando a regressäo entre as variáveis utilizadas por SWINBANK (1963), concluíram que para qualquer valor do coeficiente b da reta de regressão entre 1 e 10 , haveria um alto coeficiente de correlação.

A Figura 15 mostra que os resultados os coeficientes $a=$ 0,6453 e $b=0,0536$ obtidos pela regressão linear entre as variáveis emissividade do céu claro estimada pelo balanço de radiação e a raiz quadrada da pressão de vapor ao nivel de abrigo, permaneceram dentro do intervalo de confiança das médias obtidas por VISWANADHAM \& MASCARENHAS JR. (1978), (onde $a=0,552 \pm 0,089$ e $b=0,056 \pm 0,019$ ). O coeficiente a para o modelo ajustado de Brutsaert foi igual ao valor por 
52.

ele obtido originalmente para condições de atmosfera padrão, mas o valor original da constante b levaria a uma superestimativa da emissividade do céu claro.

A pequena faixa de variação da pressão de vapor (Tabela 1), que é característica do horário e época do ano deve ter influenciado de modo acentuado o erro padrão do coeficiente $\mathbf{b}$, apesar da magnitude do erro padrão ser inerente ao processo de medição como um todo. O baixo valor obtido para o coeficiente $\mathbf{b}$ pode estar relacionado com a baixa altitude local conforme Deacon, citado por VISWANADHAM \& MASCARENHAS JR. (1978). Por outro lado, os altos valores dos coeficientes a dos modelos ajustados de Brunt e Brutsaert podem estar relacionados çom a ocorrência de névoa seca e inversāo térmica.

As médias das diferentes estimativas apresentaram diferenças significativas em relação ao valor médio de 0,8996 , obtido por meio do balanço de radiação, como se pode observar na Tabela 9.

Tabela 9 - Emissividade média diurna estimada por equações empíricas.

\begin{tabular}{ccccc} 
& BRUNT & SWINBANK & IDSO \& JACKSON & BRUTSAERT \\
\hline Média & 0,8282 & 0,8082 & 0,8278 & 0,8573 \\
Valor de $t$ & $27,64^{* *}$ & $32,82^{\star *}$ & $25,57^{* *}$ & $16,51^{\star *}$ \\
\hline
\end{tabular}

** Valor significativo ao nível de $1 \%$ de probabilidade 
AJuste do Modelo de Brunt

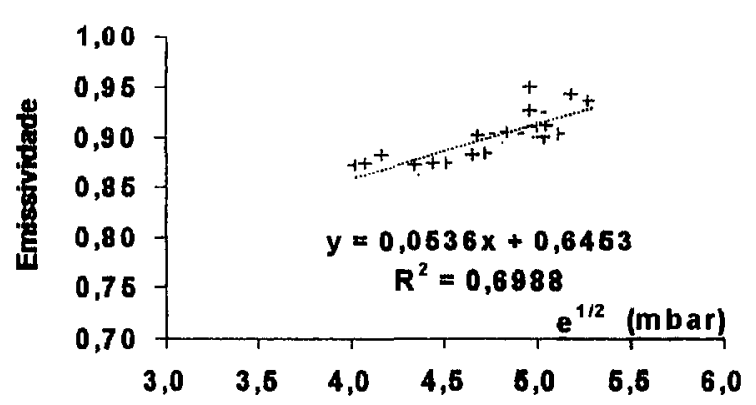

$$
+\varepsilon_{a}----\operatorname{Linear}\left(\varepsilon_{a}\right)
$$

Ajuste do Modelo de Idso \& Jackson

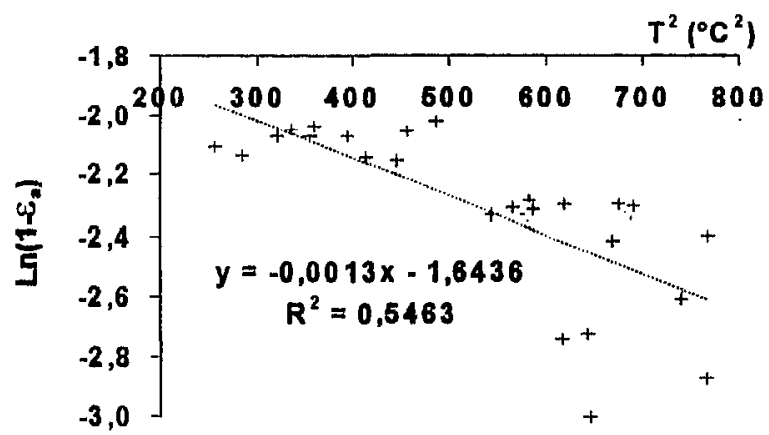

$$
+\operatorname{Ln}\left(1-\varepsilon_{a}\right)---\operatorname{Lnear} \operatorname{Ln}\left(1-\varepsilon_{a}\right)
$$

Ajuste do Modelo de Swinbank

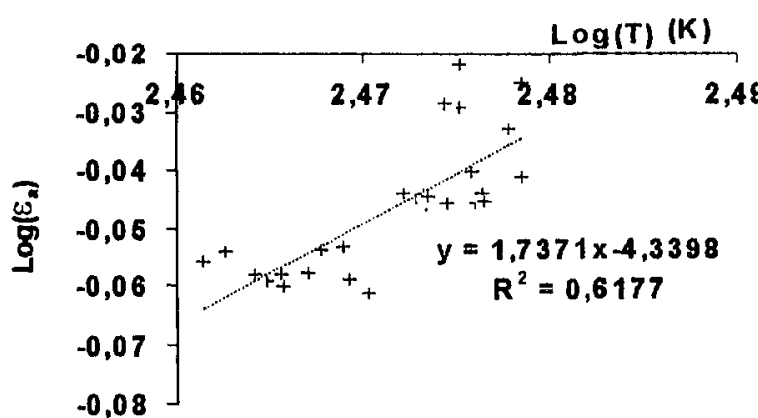

$+\log \left(\varepsilon_{a}\right) \quad--\operatorname{Linear} \log \left(\varepsilon_{a}\right)$

Ajuste do Modelo de Brutsaert

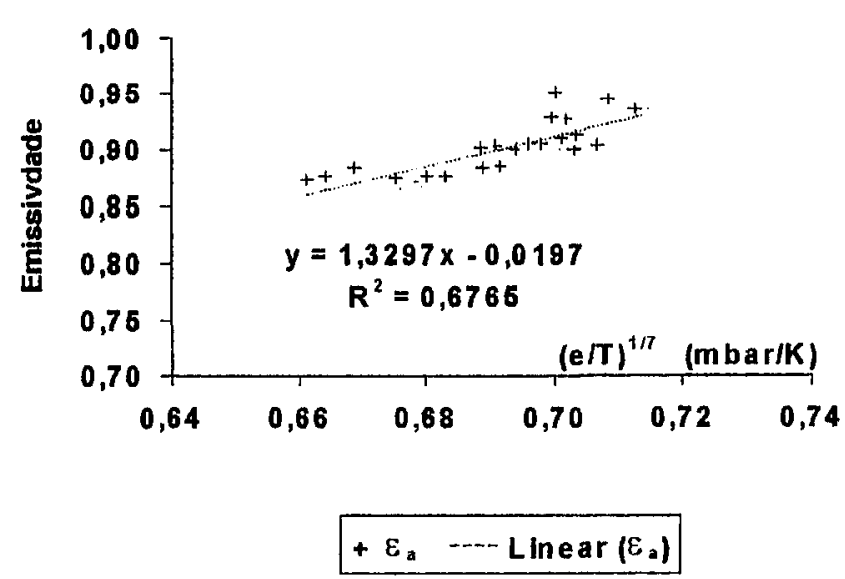

Figura 15 - Ajuste dos modelos de BRUNT (1932), SWINBANK (1963), IDSO \& JACKSON(1969) e BRUTSAERT(1975), dados noturnos. 


\subsection{Correção para a Presença de Nuvens}

Foram utilizados dois índices para quantificar a transmissividade atmosférica e avaliar seu efeito sobre a emissividade: a razão de insolação $(n / N)$ e a relação entre radiação global incidente $\left(R_{S g}\right)$ e radiação extraterrestre $\left(R_{a}\right)$

$\mathrm{Na}$ Tabela 10 podem ser observados os valores obtidos no presente estudo, onde se verifica que a razão de insolação variou entre 0,65 a 0,90 e a razão $R_{s g} / R_{a}$ variou entre 0,36 a 0,53 .

Tabela 10 - Razão entre a radiação global incidente e a radiação extraterrestre e razão de insolação.

\begin{tabular}{lccccccccc} 
Data & $12 / 07$ & $13 / 07$ & $03 / 09$ & $04 / 09$ & $10 / 09$ & $11 / 09$ & $17 / 09$ & $18 / 09$ & $22 / 09$ \\
\hline $\mathrm{R}_{\mathrm{SA}} / \mathrm{R}_{\mathrm{a}}$ & 0,53 & 0,53 & 0,42 & 0,44 & 0,42 & 0,36 & 0,39 & 0,40 & 0,39 \\
$\mathrm{n} / \mathrm{N}$ & 0,90 & 0,90 & 0,78 & 0,80 & 0,76 & 0,72 & 0,65 & 0,73 & 0,71 \\
\hline
\end{tabular}

O efeito da transmissividade, estimada por esses dois indices, foi avaliado através de regressão múltipla com duas variáveis independentes. A primeira variável constituiu em uma daquelas já usadas no ajuste local dos modelos $\left(e^{0,5}, \log (T), T^{2} e(e / T)^{1 / 7}\right)$. A segunda variável independente foi $n / N$ ou $R_{s g} / R_{a}$ para os modelos de Brunt e Brutsaert; $\log (n / N)$ ou $\log \left(R_{S g} / R_{a}\right)$ para o modelo de Swinbank; e $\operatorname{Ln}(n / N)$ ou $\operatorname{Ln}\left(R_{s g} / R_{a}\right)$ para o modelo de Idso \& Jackson.

O valor médio da razão de insolação foi de 0,77 , enquanto o valor da transmitância, conforme anteriormente citado, foi apenas de 0,43. A ocorrência de nuvens nos dias em que foram realizadas as 
medidas foram baixas e esses valores médios citados foram conseqüência da ocorrência de névoa seca e fumaça, principalmente no mês de setembro.

Tabela 11 - Coeficientes de determinação entre a emissividade obtida através do balanço de radiação e a emissividade média diária estimada por equações empíricas utilizando as relações de correção.

BRUNT SWINBANK IDSO \& JACKSON BRUTSAERT

\begin{tabular}{ccccc}
$\mathrm{R}_{\mathrm{Sa}} / \mathrm{R}_{\mathbf{a}}$ & 0,603 & 0,423 & 0,404 & 0,596 \\
$\mathrm{n} / \mathrm{N}$ & $0,612^{* *}$ & $0,396^{\star *}$ & $0,388^{* *}$ & $0,605^{\star *}$ \\
\hline
\end{tabular}

** Valor significativo ao nível de $1 \%$ de probabilidade.

Através da comparação entre a Figura 11 e a Tabela 11, verifica-se que a inclusão da segunda variável independente não produziu efeito satisfatório para explicar as variações da emissividade.

Os resultados obtidos foram condizentes com as observações de BLISS (1961), ao analisar as influências das nuvens. Se a temperatura perto do solo for de $290 \mathrm{~K}$, as nuvens contribuem para aumentar a radiação de ondas longas incidente em até $11 \%$, em uma situação de céu completamente coberto de nuvens, sendo a influência das nuvens no zênite maior que do que a das laterais. 
56.

\section{CONCLUSÕES}

As variações observadas na emissividade da atmosfera em dias sem nuvens foram melhor explicadas pela evolução da pressão de vapor no nivel do abrigo ao longo do tempo, do que pelas variações na temperatura.

Usando coeficientes locais, a emissividade estimada através dos modelos propostos por BRUNT (1932) e BRUTSAERT (1975) se mostrou mais ajustada aos resultados observados do que as estimativas obtidas pelas equações propostas por SWINBANK (1963) e IDSO \& JACKSON (1969).

O teor de gás carbônico, a razão de insolação e a razão entre a radiação global incidente e a extraterrestre não introduziram melhoras no desempenho das equações de estimativa da emissividade da atmosfera.

Para valores médios diários, o uso de qualquer uma das equaçōes analisadas permite obter estimativas da radiaçāo líquida com erros inferiores a $5 \%$, e, para efeitos práticos de estimativa da disponibilidade de energia radiante diária, qualquer uma das equaçōes proporcionaria erros inferiores a $10 \%$ da emissão efetiva.

A emissividade estimada pelo balanço de radiação entre as 20 e $21 \mathrm{~h}$ e as médias diárias não diferiram entre si. 
57.

\section{REFERÊNCIAS BIBLIOGRÁFICAS}

AASE, J.K. \& IDSO, S.B. A comparison of two formula types for calculating long-wave radiation from the atmosphere. Water Resources Research, 14(4), 623-625, 1978.

ALLEN, R.G.; JENSEN, M.E.; WRIGHT, J.L. \& BURMAN, R.D. Operatinal estimates of evapotranspiration. Agronomy Journal, 81: 650-662, 1989.

BERDAHL, P. \& FROMBERG, R. The thermal radiance of clear skies. Solar Energy, 29: 299-314, 1982.

BLISS Jr, R.W. Atmospheric radiation near the surface of the ground: A summary for engineers. Solar Energy, 5(3), 103-120, 1961.

BRUNT, D. Notes on radiation in the atmosphere. Quarterly Journal Royal Meteorological Society, 58: 389-418, 1932.

BRUNT, D. Radiation in the trophosfere. In: Physical and Dynamical Meteorology, Cambridge at the University Press, 1952. p.136-146.

BRUTSAERT, $W$. On a derivable formula for long-wave radiation from clear skies. Water Resources Research, 11: 742-744, 1975.

CENTENO, MELCHOR $V$. New formulae for equivalent night sky emissivity. Solar Energy, 28: 489-498, 1982.

De WIT, C.T. Photosynthesis of leaf canopies. Agriculture Research Report 663. Pudoc, Wageningen. 57 p. 1965. 
DOORENBOS, J. \& KASSAN, A.H. Yield response to water. Irrigation and Drainage Paper 33. FAO: Roma, 1979. 193 p.

DOORENBOS, J. \& PRUITT, W.O. Guidelines for predicting crop water requirements. Irrigation and Drainage Paper 24. FAO: Roma, 1976. $156 \mathrm{p}$.

CULF, A.D \& GASH, J.H. Longwave radiation from clear skies in Niger: A comparison of observations with simple formulas. American Meteorological Society, 32: 539-547, 1993.

DAUGHTRY, C.S.T.; KUSTAS, W.P.; MORAN, M.S. \& PINTER JR., P.J. Spectral estimates of net radiation and soil heat flux. Remote Sens. Environ. 32: 111-124, 1990.

DEACON, E.L. The derivation of Swinbank's long-wave radiation formula. Quarterly Journal Royal Meteorological Society, 11: 349356, 1972.

DAUGHTRY, C.S.T.; KUSTAS, W.P.; MORAN, M.S. \& PINTER JR., P.J. Spectral estimates of net radiation and soil heat flux. Remote Sens. Environ. 32: 111-124, 1990.

FIELD, R.T.; FRITSCHEN, L.J.; KANEMASU, E.T.; SMITH, E.A.; STEWART, J.B.; VERMA, S.B. \& KUSTAS, W.P. Calibration, comparison, and correction of net radiation instruments used during FIFE. Journal of Geophysical Research. 97: 18681-18685, 1992.

FONSECA, J.S. da; MARTINS, G. de A.; TOLEDO, G.L. In: Estatística Aplicada, 2.ed, 1989. São Paulo, Atlas, 267 p.

FOOD AND AGRICULTURE ORGANIZATION OF THE UNITED NATIONS. Guidelines for predicting crop water requeriments. Roma, 1975. 179p. 
FOOD AND AGRICULTURE ORGANIZATION OF THE UNITED NATIONS. Report on the expert consultation on procedures for revision of FAO guidelines for prediction of crop water requeriments. Roma, 1991. 45p.

HALLDIN, S. \& LINDROTH, A. Errors in net radiometry: comparison and evaluationof of six radiometer designs. Journal of Atmosferic Oceanic Technology. 9: 762-783, 1992.

HATFIELD, J.L.; REGINATO, R.J.; IDSO, S.B. Comparison of long-wave radiation calculation methods over the United States. Water Resource Research, 19(1), 285-288, 1983.

IDSO, S.B. \& JACKSON, R.D. Thermal radiation from the atmosphere. Journal of Geophysical Research, 74: 5397-5403, 1969.

INTERGOVERNMENTAL PANEL ON CLIMATE CHANGEIWMO. Scientific assessment of climate change. 1990.

LEITE,M.L.; SEDIYMA, G.C.; COELHO, D.T.; VIEIRA, H.A. Determinação da evapotranspiraçāo de equilibrio numa superfície cultivada com feijão (Phaseolus vulgaris L.), em duas densidades de plantio. Revista Ceres, 37(210): 99-110, 1990.

LONDON, J. C. The distribuition of radiational temperature change in the northern hemisfere during march. Journal Meteor., 9(145): 145$151,1952$.

MENDONÇA, E.D.D.; CAMPELO Jr, J.H.; PRIANTE Fo, N. Balanço de radiação de ondas longas em Santo Antônio do Leverger In: REUNIÃO ESPECIAL DA SBPC MATO GROSSO: NOVOS CAMINHOS, 2., Cuiabá; 1995. Anais. SBPC, São Paulo, 1995. p.16. 
MENDONÇA, M.M.D.D.; CAMPELO Jr, J.H.; PRIANTE Fo, N. Estimativa da resistência aerodinâmica à difusão do vapor d'água. In: REUNIÃO ESPECIAL DA SBPC MATO GROSSO: NOVOS CAMINHOS, 2., Cuiabá; 1995. Anais. SBPC, São Paulo, 1995. p.16.

MONTEITH, J.L. An empirical method for estimating long-wave radiation exchanges in British Isles. Quarterly Journal of the Royal Meteorological Society, 87: 171-179, 1961.

MONTEITH, J.L. Principles of Environmental Physics . Edward Arnod: London, 1973. 241 p.

NIMER, E. Climatologia do Brasil. IBGE: Rio de Janeiro, 1979. 421 p.

PAVÃO H.G \& SOUZA, A. de. A influência das queimadas no aumento da concentracão de gás carbônico atmosférico em Cuiabá In: REUNIÃO ESPECIAL DA SBPC MATO GROSSO: NOVOS CAMINHOS, 2., Cuiabá; 1995. Anais. SBPC, São Paulo, 1995. p.236.

ROSENBERG, N.J.; BLAD, B.L. \& VERMA, S.B. Microclimate - The Biological Environment. John Wiley \& Sons: New York, 1983. 495 p.

STALEY, D.O. \& JURICA, G.M. Effective atmosferic emissivity under clear skies. Journal Applied Meteorology. 11: 349-356, 1972.

SUGITA, M. \& BRUTSAERT, W. Cloud effect in the estimation of instantaneous downward longwave radiation. Water Resources Research. 19: 599-605, 1993.

SWINKANK, W.C. Long-wave radiation from clear skies. Quarterly Journal of the Royal Meteorological Society, 89: 339-348, 1963. 
61.

URIARTE, S.J.D. Estimativa da radiação global e do termo aerodinâmico da equação de Penman para Cajamarca - Perú. Viçosa, 1990. 59p. (Mestrado - Universidade Federal de Viçosa).

VISWANADHAM, Y. Infrared flux and flux divergence in clear tropical southern atmosphere. INPE-223-RI/024, São José dos Campos, 1972.

VISWANADHAM, Y. \& MASCARENHAS Jr, A.S. Avaliação do fluxo de radiação infravermelhada atmosfera em estaçöes oceânicas, Revista Brasileira de Física, São Paulo, 8(1): 1-34, jan. 1978. 
